\title{
The Deviation between the Field Measurement and ENVI-met Outputs in Winter- A Cases Study in a Traditional Dwelling Settlement of China
}

Xuan Ma ( $\nabla$ mxozil@yahoo.com )

chang'an university https://orcid.org/0000-0002-4042-7020

Jingyuan Zhao

Changan University: Chang'an University

Lei Zhang

Changan University: Chang'an University

Mengying Wang

Changan University: Chang'an University

Zhi Cheng

Kyushu University: Kyushu Daigaku

Original article

Keywords: Tradition dwelling settlement, Field measurement, ENVI-met v4.4.4, Database

Posted Date: October 22nd, 2020

DOI: https://doi.org/10.21203/rs.3.rs-94479/v1

License: (c) (1) This work is licensed under a Creative Commons Attribution 4.0 International License.

Read Full License 
The deviation between the field measurement and ENVI-met outputs in winter- A cases study in a traditional dwelling settlement of China

1 Department of Architecture, Chang'an University, China; mxozil@chd.edu.cn; zjyqtt@163.com; zl.wc@chd.edu.cn;

2 Graduate school of Human-Environment Studies, Kyushu University, Japan; 3HE18401S@s.Kyushuu.ac.jp,fordreamcz@outlook.com

* Correspondence: zjyqtt@163.com, zl.wc@chd.edu.cn;

\section{Abstract:}

Background: Numerical simulation has been used for assessing the process of outer environment performance calculations accurately. The ENVI-met has been used in studies in simulating the microclimate and energy cost in hot summer. On 27th November,2019, the latest ENVI-met v4.4.4 has been published, which is the first edition for forecasting the outdoor microclimate in winter, therefore, its accuracy is still needed to be discussed. Methods: This study aims at evaluating the effectiveness of the latest edition on the prediction of the thermal environment of courtyard and outdoor space in a traditional dwelling settlement in cold climate zone of northern China by means of validating the measured results against simulated results. Results: The final result shows a small deviation between simulated and measured results for assessing the microclimate in the research site. Conclusions: For this reason, the new ENVI-met v4.4.4 can be a reliable tool for forecasting the winter microclimate in northern China, and also this study also provides a basic database for improving resident's thermal comfort in cold climate zone of China in future studies.

Keywords: Tradition dwelling settlement; Field measurement; ENVI-met v4.4.4; Database

\section{Introduction}

As society develops, architects and urban planners have faced the important task of designing the suitable outdoor and indoor environment for human while saving energy [1]. In developed countries, the building energy cost occupies $40 \%$ of the total energy used in humans' daily lives [2], in China, the building energy consumption has increased by nearly $45 \%$ in the last two decades under the rapid development of the urbanization [3-5]. To design and ensure a healthy and comfortable indoor and outdoor environment for human is very necessary. To this content, a special attention must be focused on the factors of the buildings that can make a contribution to the passive conditioning, such as the Chinese traditional courtyard. The courtyard in Chinese traditional building has different functions in daily lives such as providing light, ventilation and so on. As an important factor of passive conditioning, the courtyard plays an important role in affecting outdoor environment, accelerated by the higher energy cost that people are facing today, also it has been tested for an important element for cooling on buildings in cities [6].

The cave dwelling is an ancient residential form in northern China, which also has more than 4000 years history [7]. So far, there are still too many people living here, therefore, many governments and civil organizations have taken some measures to improve living environment in such traditionalstyle dwellings. The microclimate in the cave-dwelling is affected by different kinds of elements such as vegetation, water body wind and geometry of this region [8,9]. All of them will affect the distribution of air temperature in the courtyard. In the aspect of the cave dwelling, courtyard can play an important role in the design of zero energy cost buildings. 
As technology develops, the utilization of simulated process based on the Computational Fluid Dynamics (CFD) is becoming popular. Among the development, we can find Design Builder, ANSYS Fluent and ENVI-met are the most popular three. Design Build provides a platform for assessing architecture energy consumption hat has been reported not to reflect the true air temperature in outdoor courtyard [10]. ANSYS Fluent can be used to simulate the turbulence and fluid models, it needs a not proportional amount of effort and time to be applied the researched target [11].Since we aim at discussing the microclimate in the courtyard, the most suitable tool is the software ENVI-met, which we will introduce as follows. This tool can be able to analyze the interactions between outdoor microclimate and air, soil, vegetation and buildings. Based on this reason, it's been used in many studies about urban microclimate, in which it provides a platform with a horizontal resolution from 0.5 to $5 \mathrm{~m}$ and a time frame of $24-48 \mathrm{~h}$ with a time step $1-5 \mathrm{~s}$. It also has been accepted for many studies in the research about outdoor thermal environment in summer [12-20]. Table.1 provides a series of papers that use some statistical parameters for validating the accuracy of the simulated results by ENVI-met against on-site measurement data. The used parameters are the Root Mean Square Error (RMSE) and the Coefficient of Determination (R2), in order to build a reliable model for simulation, mentioned two indices must be tended to the following values: RMSE $\rightarrow 0, R^{2} \rightarrow 1$.

Table. 1 The comparison of the measured and simulated data in previous cases

\begin{tabular}{llllll}
\hline \multicolumn{1}{c}{ Authors } & R2 & $\begin{array}{l}\text { RMSE( } \\
\left.{ }^{\circ} \mathrm{C}\right)\end{array}$ & Season & Area & Location \\
\hline Ma et al. [12] & 0.98 & 1.1 & Summer & Urban block & Foshan \\
Yang et al [13] & 0.94 & 1.01 & Summer & Urban park & Guangzhou \\
Wang et al [14] & 0.89 & - & Summer & Urban distract & Beijing \\
Qaid and Ossen [15] & 0.69 & 1.82 & Summer & Urban Boulevard & Putrajaya \\
Lee et al [16] & 0.85 & 0.66 & Summer & Urban area & Freiburg \\
Jänicke et al[17] & 0.89 & 1.35 & Summer & Urban facade & Berlin \\
Hedquist et al[18] & 0.89 & 2.9 & Summer & Urban & Phoenix \\
Ketter et al [19] & 0.88 & 0.28 & Summer & Courtyard & Stuttgart \\
Song and Park [20] & 0.52 & 4.83 & Summer & Urban open space & Changwon \\
\hline
\end{tabular}

It's obvious that we can obviously find the results of mentioned studies are very various, the RMSE ranging from 0.28 to 4.83 , and the $\mathrm{R}^{2}$ being within $0.52-0.98$. In addition, very limited study is focused on analyzing the microclimate in courtyards by ENVI-met, especially in cold winter. For this reason, the main purpose of this study aims at testing the accuracy of the ENVI-met whether can be a reliable tool in forecasting the microclimate and energy cost of the cave dwelling in the winter. This study uses the ENVI-met v4.4.4 to conduct the final work, which is the first edition for simulating outdoor environment in the winter. The current findings will bring a new direction for researching people's thermal sensation and a new way to assess the outdoor energy consumption in the winter.

\section{Background information}

\subsection{Analyzed site: Ancient cave settlement in Mi Zhi}

The Mi Zhi city is in the northern part of Shaanxi province, China, which is also a preservation of cultural relics (Figure.1). Mi Zhi is geographically located between $37^{\circ} 39^{\prime} \mathrm{N}$ and $38^{\circ} 5^{\prime} \mathrm{N}$ latitude and $109^{\circ} 49^{\prime} \mathrm{E}$ and $110^{\circ} 29^{\prime} \mathrm{E}$ longitude, which means this city is in the continental monsoon climate zone. According to the Chinese climate divisions for buildings, Mi Zhi city belongs to the severe cold zone (Figure.2). Its annual mean air temperature is $8.5^{\circ} \mathrm{C}$, and the extreme temperature in winter can drop down to $-25.5^{\circ} \mathrm{C}$ [21].

The ancient cave dwelling settlement (Figure.3) is a very old residential area in the Mi Zhi city, which is built in the time of Ming dynasty (1368-1644) and the early of Republic of China (1912-). The whole region is composed of different buildings and courtyards. In addition, this area is listed as a preservation of cultural relics by the United Nations [22]. 


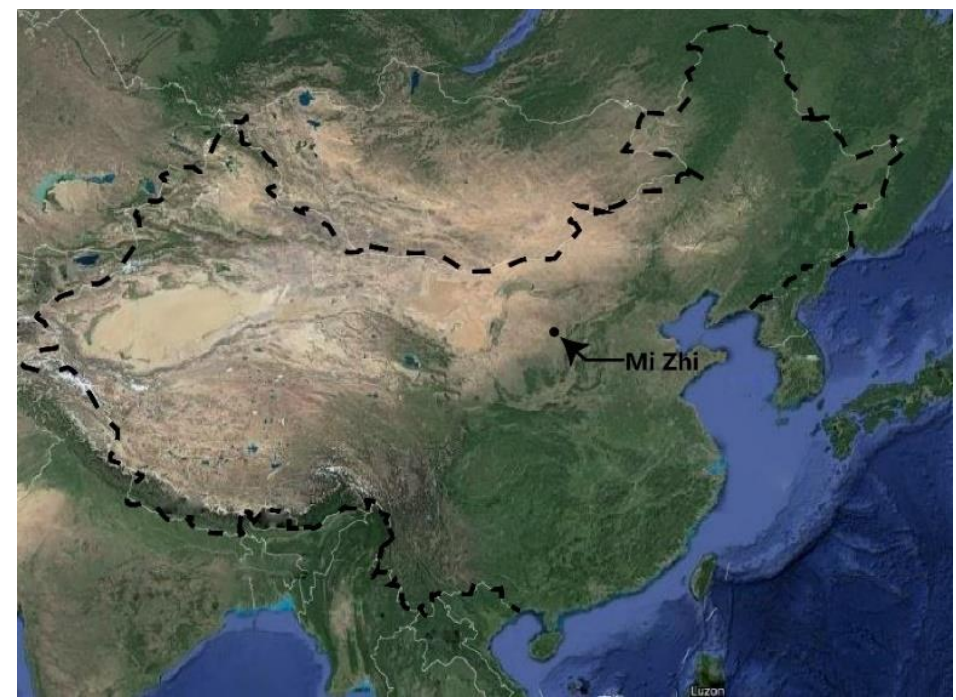

Figure. 1 The location of the Mi Zhi city

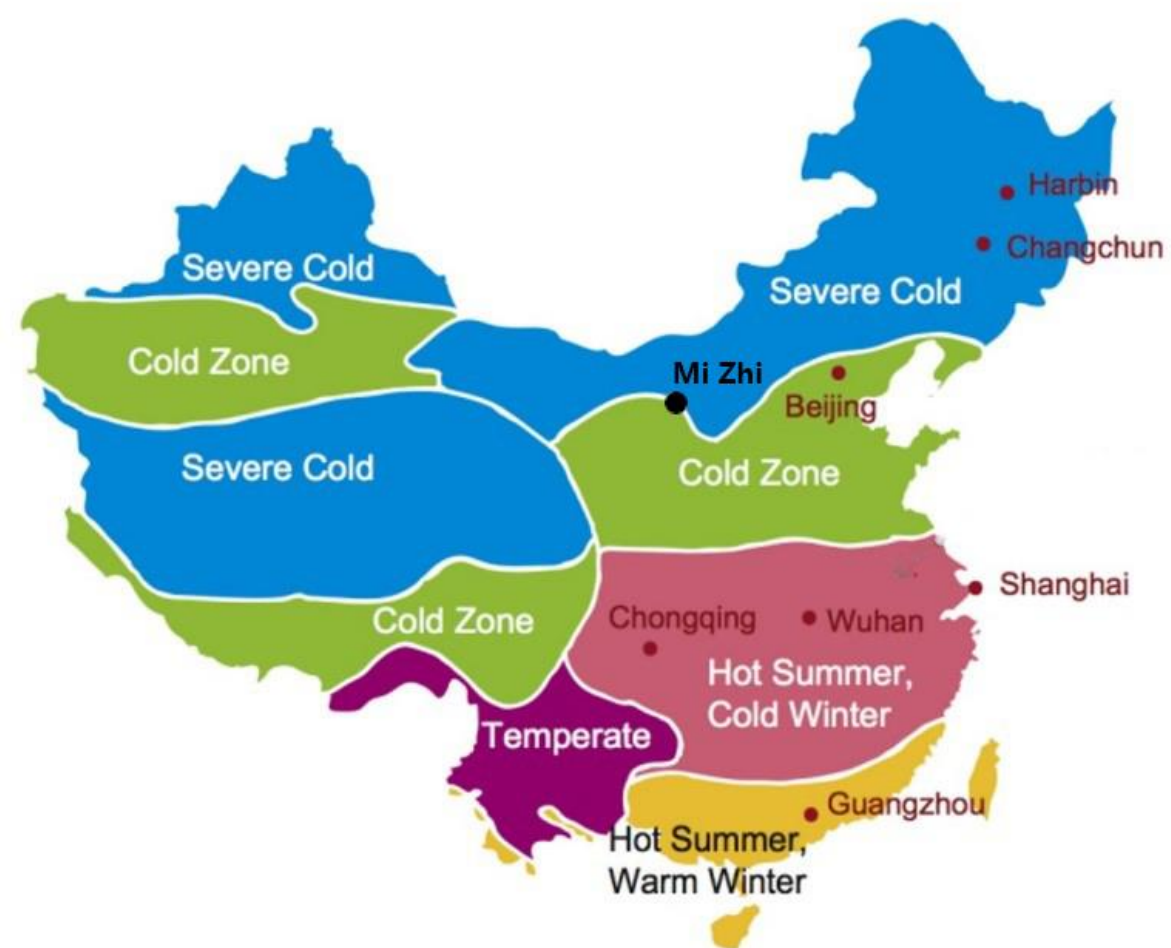

Figure. 2 The climate zone of the Mi Zhi city

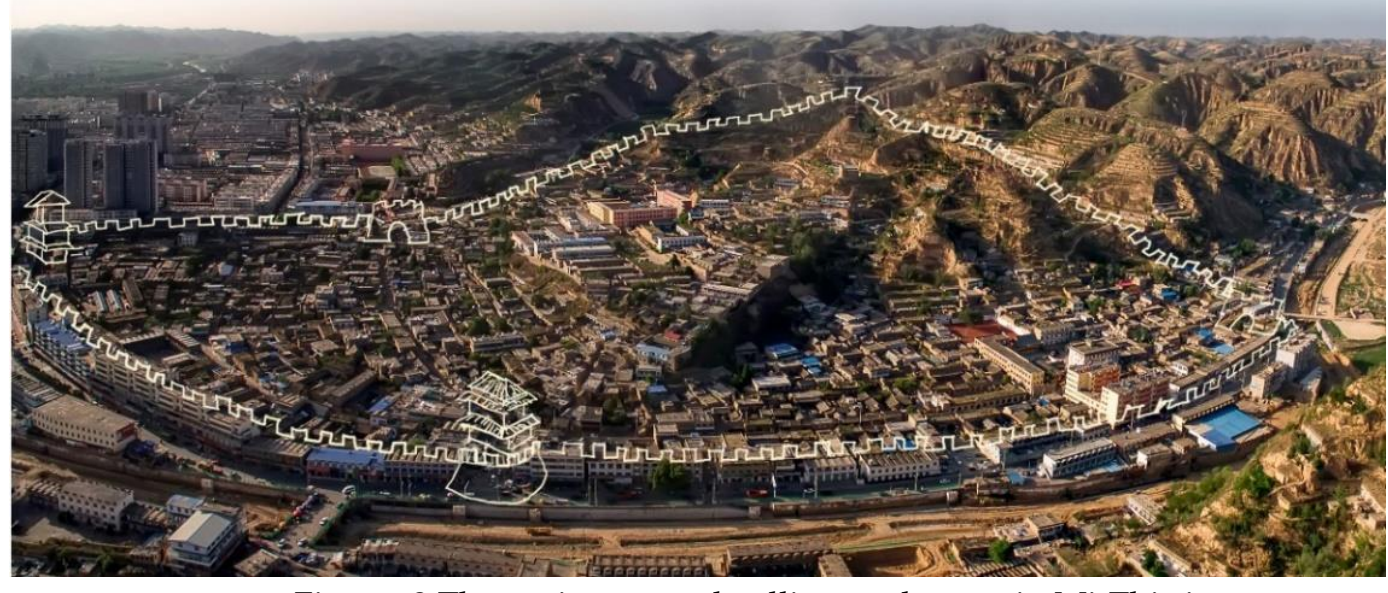

Figure. 3 The ancient cave dwelling settlement in Mi Zhi city 
As is shown in Figure. 4, the old traditional buildings in this settlement all have the courtyards and have a long history, however, the living conditions here are very poor. Also, many of families have lived here for a few generations.

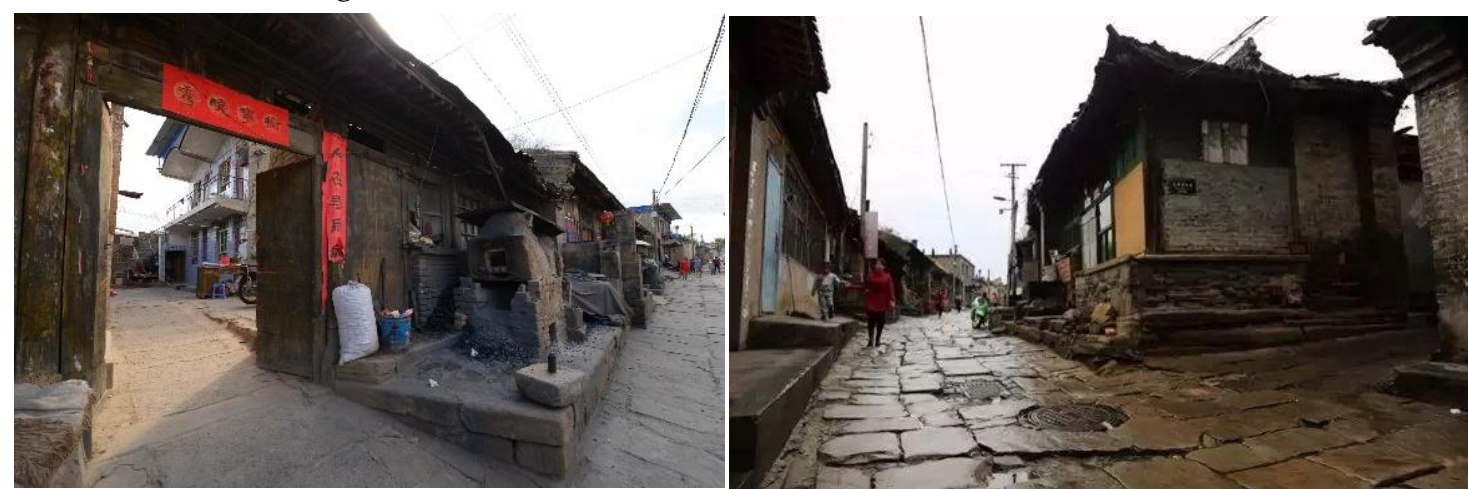

Figure. 4 The existing dwellings in Mi Zhi city

\subsection{Analyzed site: Ancient cave settlement in Mi Zhi}

The software ENVI-met is evaluated for analyzing microclimate through the basic principle of thermodynamics and fluids, which can be a tool to simulate the interactions between air, vegetation, soil and buildings. In this platform, it's designed for the Three-D modelling with a typical horizontal resolution from 0.5 to $5 \mathrm{~m}$, the typical simulated time is $24-48 \mathrm{~h}$ with a time step of $1-5 \mathrm{~s}$ (Figure.5). This design can allow the analysis of middle and small-scale interactions between vegetation, surface and outdoor buildings [23].

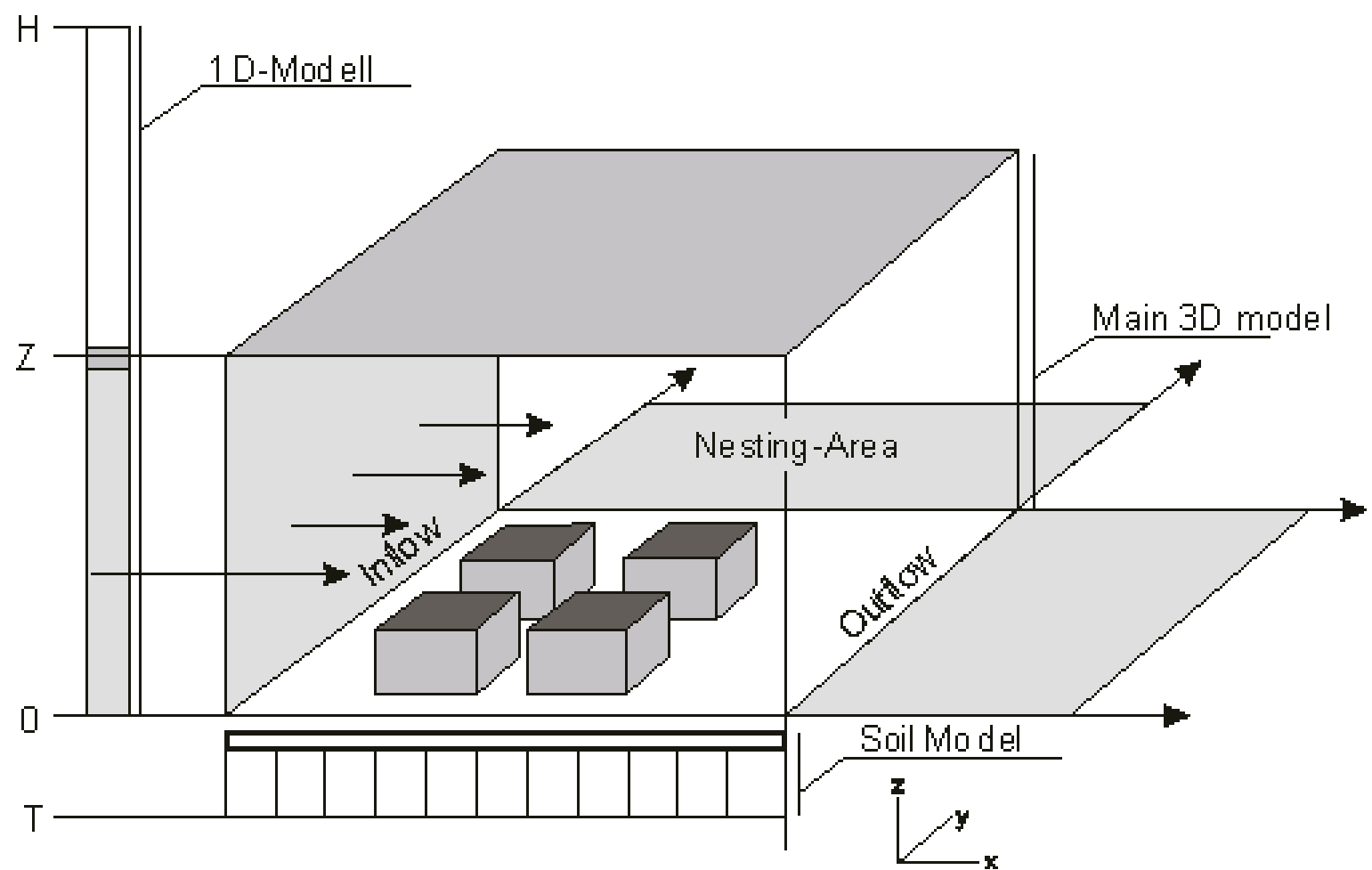

Figure. 5 The schematic overview of the ENVI-met model

In this software platform, the fundamental equations from the physical model are corresponding with 1) mean air flow, 2) temperature and humidity, 3) turbulence and exchange process, and 4) radiative fluxes, in addition, this software also includes biometeorological and particle dispersion models. In this study, the air temperature is described as the example:

The potential air temperature $\theta$ could be calculated by the utilization of the combined advectiondiffusion equations: 
$109 \quad k_{h}$ is the turbulent exchange coefficient for heat, $Q_{\theta}$ is utilized to define the heat 110 exchange between plants and air, LAD is the leaf area density, $J_{f, h}$ is the heat flux, and $T_{f}$ is the 111 foliage temperature, Ta is the air temperature.

The $\frac{1}{\rho c_{p}} \frac{\partial R_{l w}}{\partial z}$ is the change in air temperature under the effect of divergence of the long wave radiation, and the long wave radiation fluxes can be simply written as:

$\bar{T}_{f+}^{4}$ and $\bar{T}_{f-}^{4}$ are the average foliage temperature of the overlying and underlying vegetation layer, $T_{0}^{4}$ is the ground surface temperature, $\bar{T}_{w}^{4}$ is the surrounding average surface temperature of the walls, $\varepsilon_{f}, \varepsilon_{s}$ and $\varepsilon_{w}$ are the emissivity of the foliage, the ground and the walls, and $\sigma_{B}$ is the Stefan-Boltzman constant, which is $5.67 \cdot 10^{-8} \mathrm{~W} \mathrm{~m}^{-2} \mathrm{~K}^{-4}$, the $\sigma_{s v f}$ (sky view factor) is a measurement for the whole sky seen from the center of a grid cell, and $\omega$ is the maximum cutoff angle in spatial direction $\pi$.

In the process of the simulation, the ENVI-met has the shortcoming. For example, the incoming longwave radiation is an important factor for affecting air temperature, which is emitted by building, ground and plant are only calculated by mean temperature, not on the single surfaces. This will lead to a small error in simulating microclimate in the ENVI-met [23].

Based on the mentioned reasons, the latest ENVI-met v4.4.4 is released on 27th, November,2019, which is the first edition can forecast outdoor air temperature in cold winter, and the accuracy is still necessary to be discussed.

\section{Methodology}

\subsection{Survey methodology}

In our study, the field survey and simulated work are conducted from 29th, Jan to 1st Feb,2019 (Table 2). According to the published weather information by local meteorological stations, the measured days are the coldest period of one year, which also means the collected data has the typical meaning. Also, the process of this study includes two steps. Firstly, the simultaneous on-site measurement of the selected courtyards and outdoor spaces for collecting the data. Secondly, the simulated process of the selected points under ENVI-met v 4.4.4. Results of these two steps are compared, in order to assess the final conclusions of this study about the function of this software for its utilization in the outdoor environment designing process and energy cost in cold winter.

Table. 2 The meteorological data during the measured days

\begin{tabular}{clcccc}
\hline \multicolumn{1}{c}{ Date } & Weather & $\begin{array}{c}\text { Max air } \\
\text { temperature }\end{array}$ & $\begin{array}{c}\text { Min air } \\
\text { temperature }\end{array}$ & $\begin{array}{c}\text { Relative } \\
\text { humidity }\end{array}$ & Wind velocity \\
\hline 29th, January & Cloudy & $6^{\circ} \mathrm{C}$ & $-6^{\circ} \mathrm{C}$ & $30 \%$ & $1.0 \mathrm{~m} / \mathrm{s}$ \\
30th, January & Cloudy & $1{ }^{\circ} \mathrm{C}$ & $-11^{\circ} \mathrm{C}$ & $25 \%$ & $1.0 \mathrm{~m} / \mathrm{s}$ \\
31th, January & Snow & $-2^{\circ} \mathrm{C}$ & $-16^{\circ} \mathrm{C}$ & $25 \%$ & $1.5 \mathrm{~m} / \mathrm{s}$ \\
1st, February & Sunny & $3^{\circ} \mathrm{C}$ & $-10^{\circ} \mathrm{C}$ & $30 \%$ & $1.5 \mathrm{~m} / \mathrm{s}$ \\
\hline
\end{tabular}


The on-site measurement for collecting air temperature (Ta) and relative humidity (Rh) start from 9:00am to 6:00pm, all the measured days are windless and cloudless. The utilized instrument in this study is a stable meteorological station called HOBO MX2300, Table 3 shows the detailed information of the used instrument.

Table 3 The measured variables and parameter of the instrument

\begin{tabular}{|c|c|c|c|c|c|}
\hline Sensor & Variable & Accuracy & Range & Interval & Resolution \\
\hline \multirow{3}{*}{ MX2300 } & $\mathrm{T}\left({ }^{\circ} \mathrm{C}\right)$ & $\pm 0.2^{\circ} \mathrm{C}$ & $-40^{\circ} \mathrm{C}-70$ & $1 \mathrm{~min}$ & $0.04^{\circ} \mathrm{C}$ \\
\hline & & & & & \\
\hline & $\operatorname{Hr}(\%)$ & $\pm 2.5 \%$ & $0-100 \%$ & $1 \mathrm{~min}$ & $0.01 \%$ \\
\hline
\end{tabular}

After the field survey by researchers, the whole settlement is divided into 9 points (Figure 6) in accordance with different spatial characteristic (Figure 7), these selected points include four outdoor points (Point-1, Point-2, Point-3 and Point-4) and five courtyard points (Point-5, Point-6, Point-7 ,Point-8 and Point-9) (Table 4). In addition, a hemisphere photo at $1.5 \mathrm{~m}$ in each selected point is taken by using a fish-eye camera, the measured SVF (Sky View Factor) is calculated by software Ray-man, which will be validated against by simulated results in ENVI-met platform

Figure 6 The selected points in the on-site measurement

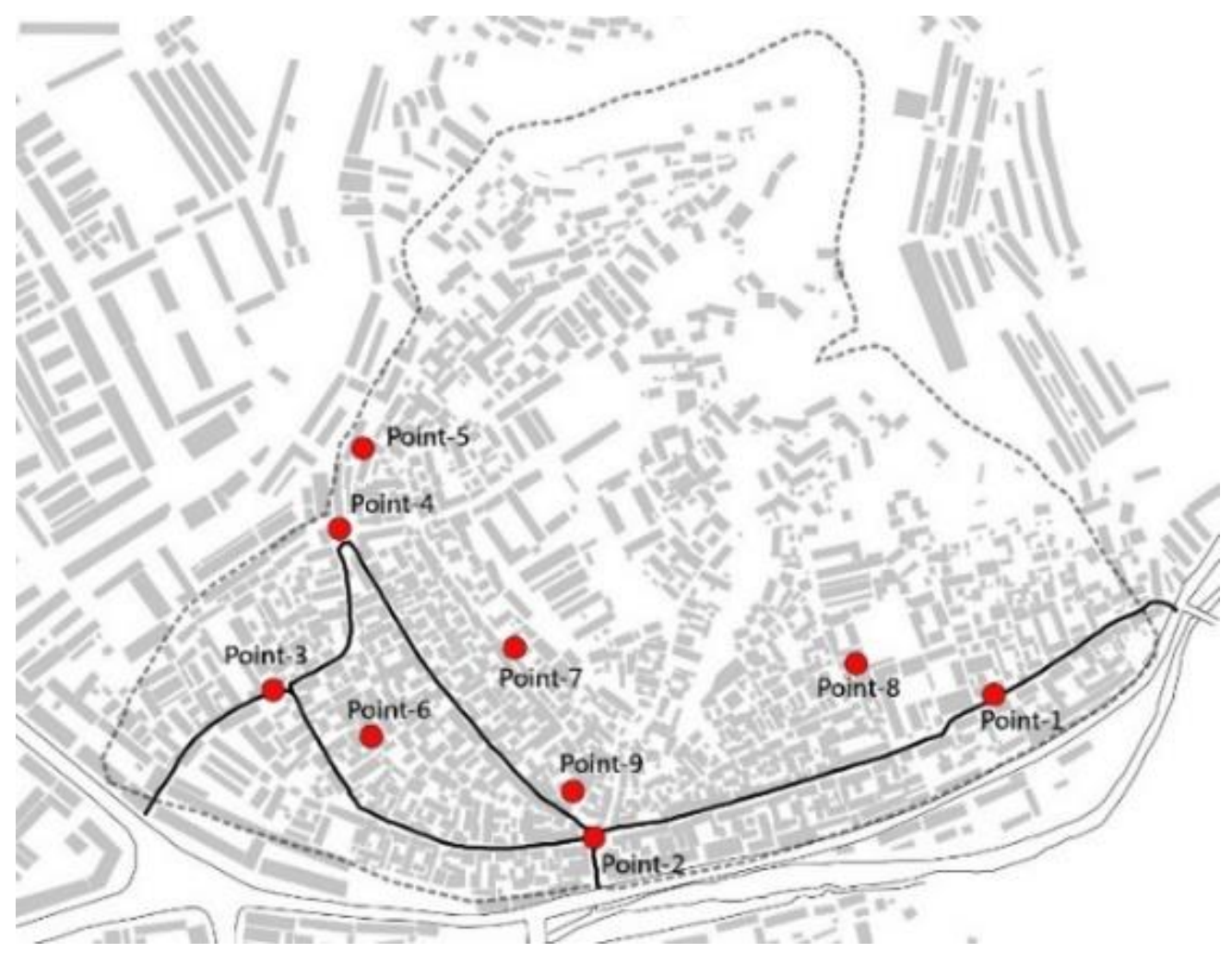

160

161

162

163

164

To be mentioned, all the points in courtyard are conducted in all the measured days. Different from courtyard, each selected point in outdoor space is carried out in every measured day, the former three points are conducted on January (29th, 30th, 31th), and point- 4 is carried out on February 1 st. Table 4 shows the detailed characteristics of each selected point.

Table 4 The geometric characteristics of the selected points

\begin{tabular}{llllll}
\hline Point & $\begin{array}{r}\text { Aspect } \\
\text { Ratio(H/W) }\end{array}$ & Height $(\mathrm{m})$ & Dimension(m) & SVF & Albedo \\
\hline 1 & 1.5 & 18 & - & 0.61 & 0.8 \\
2 & 0.13 & 6 & - & 0.63 & 0.8 \\
3 & 0.18 & 9 & - & 0.76 & 0.6 \\
4 & 0.48 & 15 & - & 0.62 & 0.8 \\
5 & 0.15 & 6.6 & $27 \times 4.2$ & 0.79 & 0.8 \\
6 & 0.5 & 3.3 & $12 \times 6$ & 0.61 & 0.8 \\
7 & 0.06 & 6.6 & $30 \times 25$ & 0.93 & 0.8 \\
\hline
\end{tabular}




\begin{tabular}{llllll}
\hline 8 & 0.35 & 3.3 & $6.8 \times 13.2$ & 0.85 & 0.8 \\
9 & 0.8 & 4.5 & $12.5 \times 4$ & 0.73 & 0.8 \\
\hline
\end{tabular}

165
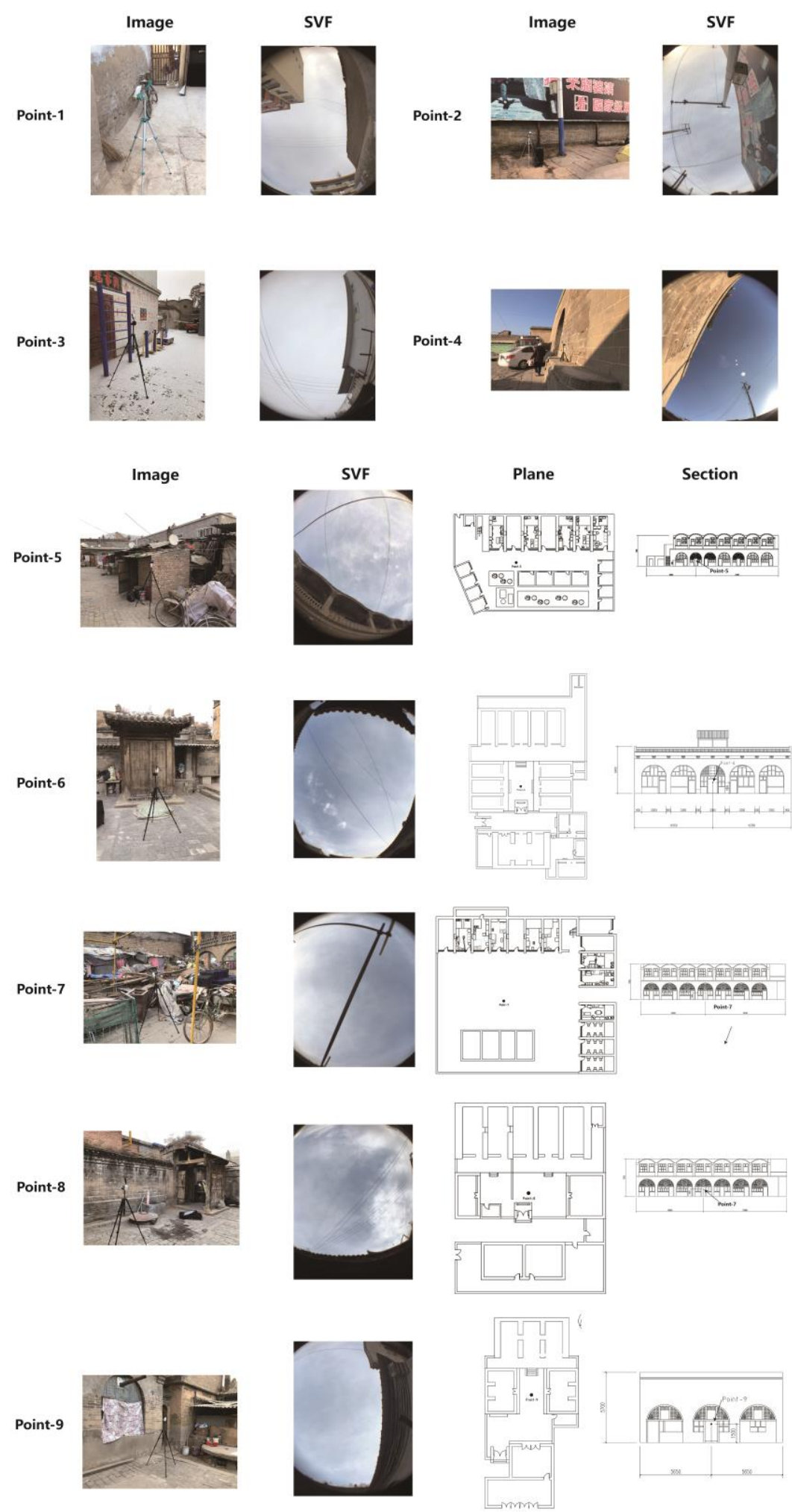

Figure 7 The detailed information of the selected points 
The first step is the on-site measurement, and the second step is the numerical simulation of the thermodynamic performance of the selected sites in winter with software ENVI-met v4.4.4, and we build the 3D model in accordance with the true size of the building and street under the field survey.

In this study, the whole simulation is conducted in total 96 hours (4 days), because the limited simulated period of this software is only 48 hours, so the whole process is divided into two parts. The first part is over a 48-hour period, starting from midnight 00:00, Jan 29th, 2019 with calculations every one minute, the simulated results were output on an hourly basis, and the initial input meteorological data in the simulated process is shown in Table 5, 6 and 7.

Table 5 Initial settings of this study

\begin{tabular}{|c|c|c|c|}
\hline Parameters & & Value & \\
\hline \multirow{12}{*}{ Materials } & \multirow{3}{*}{ Grey brick } & $\begin{array}{l}\text { Roughness } \\
\text { length }\end{array}$ & 0.01 \\
\hline & & Albedo & 0.3 \\
\hline & & Emissivity & 0.9 \\
\hline & \multirow{3}{*}{ Concrete } & $\begin{array}{l}\text { Roughness } \\
\text { length }\end{array}$ & 0.01 \\
\hline & & Albedo & 0.4 \\
\hline & & Emissivity & 0.9 \\
\hline & \multirow{3}{*}{ Mortar } & $\begin{array}{l}\text { Roughness } \\
\text { length }\end{array}$ & 0.01 \\
\hline & & Albedo & 0.8 \\
\hline & & Emissivity & 0.9 \\
\hline & \multirow{3}{*}{ Tile } & $\begin{array}{l}\text { Roughness } \\
\text { length }\end{array}$ & 0.01 \\
\hline & & Albedo & 0.5 \\
\hline & & Emissivity & 0.9 \\
\hline \multirow{9}{*}{$\begin{array}{l}\text { Boundary } \\
\text { conditions }\end{array}$} & $\begin{array}{l}\text { Air temperature } \\
\text { Relative humidity } \\
\text { Turbulent model }\end{array}$ & \multicolumn{2}{|c|}{ Table 6 and Table 7} \\
\hline & $\begin{array}{l}\text { Wind } \\
\operatorname{speed}(\mathrm{m} / \mathrm{s})(10 \mathrm{~m})\end{array}$ & \multicolumn{2}{|l|}{$1.0 \mathrm{~m} / \mathrm{s}$} \\
\hline & Wind direction $\left(^{\circ}\right)$ & \multicolumn{2}{|l|}{145} \\
\hline & Grid in $d x(m)$ & \multicolumn{2}{|l|}{4} \\
\hline & Grid in dy $(m)$ & \multicolumn{2}{|l|}{4} \\
\hline & Grid in $\mathrm{dz}(\mathrm{m})$ & \multicolumn{2}{|l|}{2} \\
\hline & Number of $x$ grid & \multicolumn{2}{|l|}{200} \\
\hline & Number of y grid & \multicolumn{2}{|l|}{200} \\
\hline & Number of $z$ grid & \multicolumn{2}{|l|}{20} \\
\hline \multirow{8}{*}{ Simulation } & \multicolumn{3}{|l|}{ Stage-1 } \\
\hline & Starting day & \multirow{3}{*}{\multicolumn{2}{|c|}{$\begin{array}{l}\text { 29th, Jan,2019 } \\
0: 00 \\
48 \mathrm{~h}\end{array}$}} \\
\hline & Starting time & & \\
\hline & Simulation time & & \\
\hline & \multicolumn{3}{|l|}{ Stage-2 } \\
\hline & Starting day & \multicolumn{2}{|l|}{ 31th, Jan,2019 } \\
\hline & Starting time & \multicolumn{2}{|l|}{$0: 00$} \\
\hline & Simulation time & \multicolumn{2}{|l|}{$48 \mathrm{~h}$} \\
\hline
\end{tabular}

Table 6 Initial air temperature and relative humidity in stage-1

Air Relative Air

Time temperature humidity

Time temperature

Relative

$\left({ }^{\circ} \mathrm{C}\right)$

(\%)

humidity (\%)

0:00

$-7.0$

34.1

$12: 00$

2.1 


\begin{tabular}{|c|c|c|c|c|c|}
\hline $1: 00$ & -8.1 & 35.5 & $13: 00$ & 3.2 & 22.3 \\
\hline 2:00 & -8.5 & 36 & $14: 00$ & 5.1 & 21.9 \\
\hline 3:00 & -9.0 & 39.1 & $15: 00$ & 4.0 & 22.1 \\
\hline 4:00 & -8.6 & 38.2 & $16: 00$ & 3.5 & 24.3 \\
\hline 5:00 & -7.5 & 37.5 & $17: 00$ & 3.2 & 25.5 \\
\hline 6:00 & -7.0 & 34.5 & $18: 00$ & 2.1 & 26.6 \\
\hline 7:00 & -6.8 & 32.5 & 19:00 & 0.8 & 27.3 \\
\hline 8:00 & -6.3 & 31.8 & $20: 00$ & -1.1 & 28 \\
\hline 9:00 & -6.0 & 30.7 & 21:00 & -3.5 & 28.8 \\
\hline 10:00 & -5.0 & 30 & $22: 00$ & -4.9 & 30.5 \\
\hline 11:00 & -1.5 & 26.2 & $23: 00$ & -6.1 & 32.5 \\
\hline \multicolumn{6}{|c|}{ Table 7 Initial air temperature and relative humidity in stage- 2} \\
\hline Time & $\begin{array}{c}\text { Air } \\
\text { temperature } \\
\left({ }^{\circ} \mathrm{C}\right) \\
\end{array}$ & $\begin{array}{c}\text { Relative } \\
\text { humidity } \\
(\%)\end{array}$ & Time & $\begin{array}{c}\text { Air } \\
\text { temperature } \\
\left({ }^{\circ} \mathrm{C}\right) \\
\end{array}$ & $\begin{array}{r}\text { Relative } \\
\text { humidity (\%) }\end{array}$ \\
\hline $0: 00$ & -11.9 & 34.9 & $12: 00$ & -4.9 & 21.5 \\
\hline 1:00 & -12.5 & 36.8 & 13:00 & -3.5 & 19.8 \\
\hline 2:00 & -15.4 & 37.1 & 14:00 & -2.0 & 16.5 \\
\hline 3:00 & -16.1 & 38.8 & 15:00 & -2.1 & 18.6 \\
\hline 4:00 & -14.5 & 36.8 & $16: 00$ & -2.5 & 22.5 \\
\hline 5:00 & -12.8 & 34.5 & $17: 00$ & -2.9 & 25.0 \\
\hline $6: 00$ & -11.5 & 32.8 & $18: 00$ & -3.5 & 27.1 \\
\hline 7:00 & -10.9 & 32.1 & 19:00 & -4.9 & 28.9 \\
\hline 8:00 & -10.1 & 31.5 & $20: 00$ & -5.5 & 29.5 \\
\hline 9:00 & -8.9 & 31.1 & $21: 00$ & -6.8 & 30 \\
\hline 10:00 & -6.8 & 27.3 & $22: 00$ & -9.5 & 31.1 \\
\hline 11:00 & -5.9 & 23.5 & $23: 00$ & -10.5 & 32.5 \\
\hline
\end{tabular}

\section{Results}

\subsection{The monitoring results (on-site measurement)}

In order to evaluate outdoor thermal environment, the index RMSE (root-mean-square error) is calculated for checking deviation. This index is a normally used in validating the gap between the observed and the predicted values, which is an important factor for testing the simulated results [60, 61]. If this index can approach or reach 0 , the most accurate results are obtained. A lower RMSE values represent that the simulated data is closed to measured result. Figure. 10 shows the index-RMSE between the simulated and measured result.

The final results of the air temperature of the on-site measurement during the measured period is shown in Figure 8. It is very obvious that the maximum air temperature appears from 13:00 to 14:00, ranging from $0.31^{\circ} \mathrm{C}$ to $10.71^{\circ} \mathrm{C}$, in addition, the minimum air temperature changes from -11.62 ${ }^{\circ} \mathrm{C}$ to $1.66^{\circ} \mathrm{C}$ at 9:00. In the first measured day (29th Jan), the air temperature in courtyard space is higher than in outdoor space, that's can be attributed to the position of the measured instrument, the point-1 has a very high $\mathrm{H} / \mathrm{W}$ at daytime, which will impede solar radiation at daytime and supply shading for this site. The selected courtyard points including point-5 and point-7 have a higher air temperature than other points, that is due to the fact that the courtyard with a lower $\mathrm{H} / \mathrm{W}$ and higher SVF can allow the daytime radiation to reach the lowest level of the site. In the second measured day (30th Jan), the outdoor point (point-2), in open space with a higher SVF, also has a higher air temperature than other points. Like the situation in the first day, the courtyard points including point-5 and point-7, with a higher SVF and lower $\mathrm{H} / \mathrm{W}$, are nearly $1.5^{\circ} \mathrm{C}$ higher than other points in courtyard space at peak time. The third measured day (31th Jan) is a snowy day, also the coldest day of this year in accordance with the published meteorological data by the local weather stations.

Different from the former two days, the changing trend of the curves tend to be smaller. Meanwhile, the courtyard point (point-5) displays the best performance, in which the air temperature 
can rise to above $0^{\circ} \mathrm{C}$ from 13:00 to 14:00. In the last measured day (1st Feb), because of the snow in 204 the former day, the air temperature is still very low in the morning. Similar to the former mentioned three days, the point- 5 and point- 7 have a higher air temperature at daytime. temperature not only in outdoor space but also in courtyard space. 


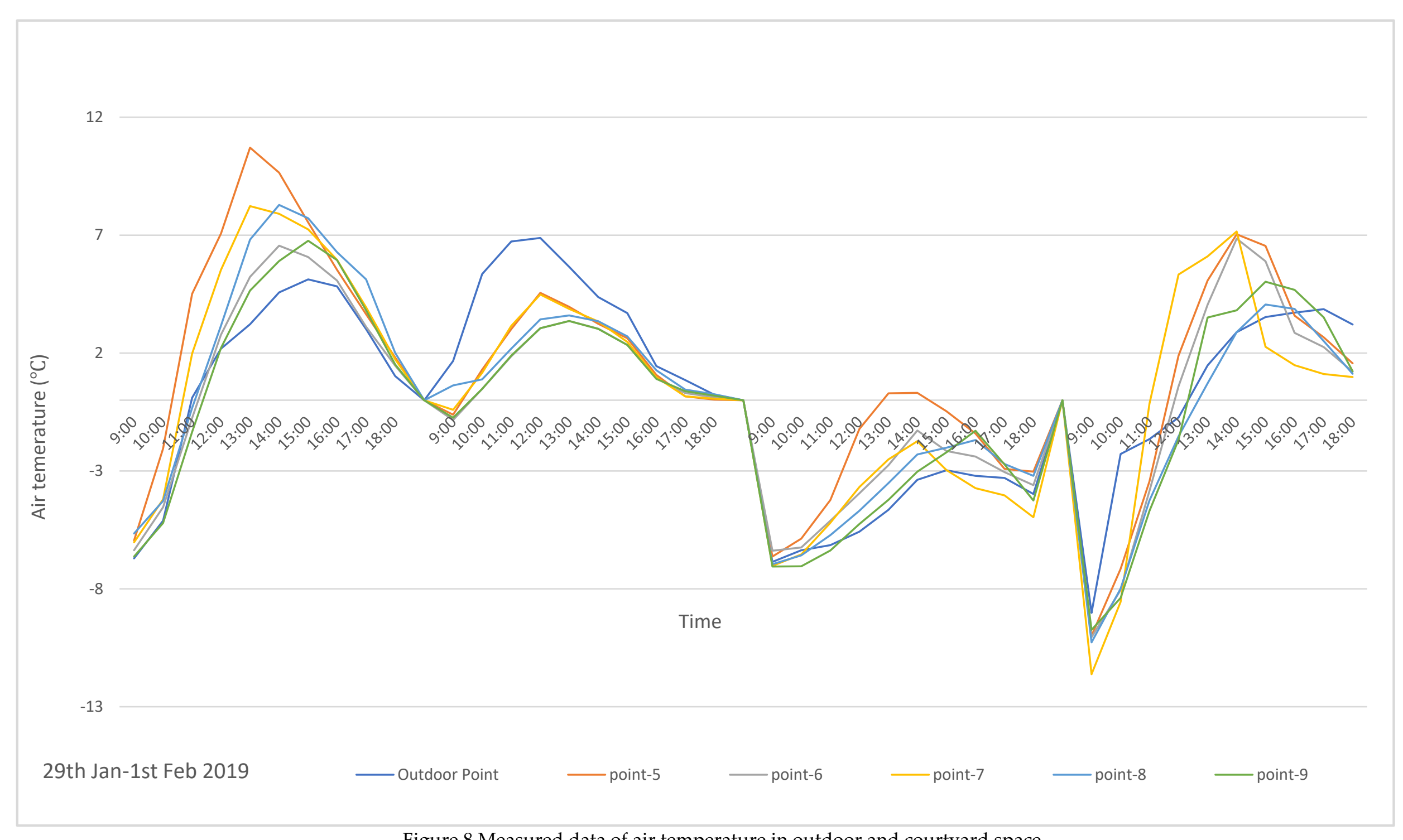


It is true that the ENVI-met can be a reliable tool for predicting the air temperature in hot summer [24-30]. Considering the interest of this study, the predication in cold winter is still very necessary, especially in the latest software platform. The simulated data in this study is collected from the points in outdoor space and courtyard (the same locations of the on-site measurement), as is shown in Figure 9.

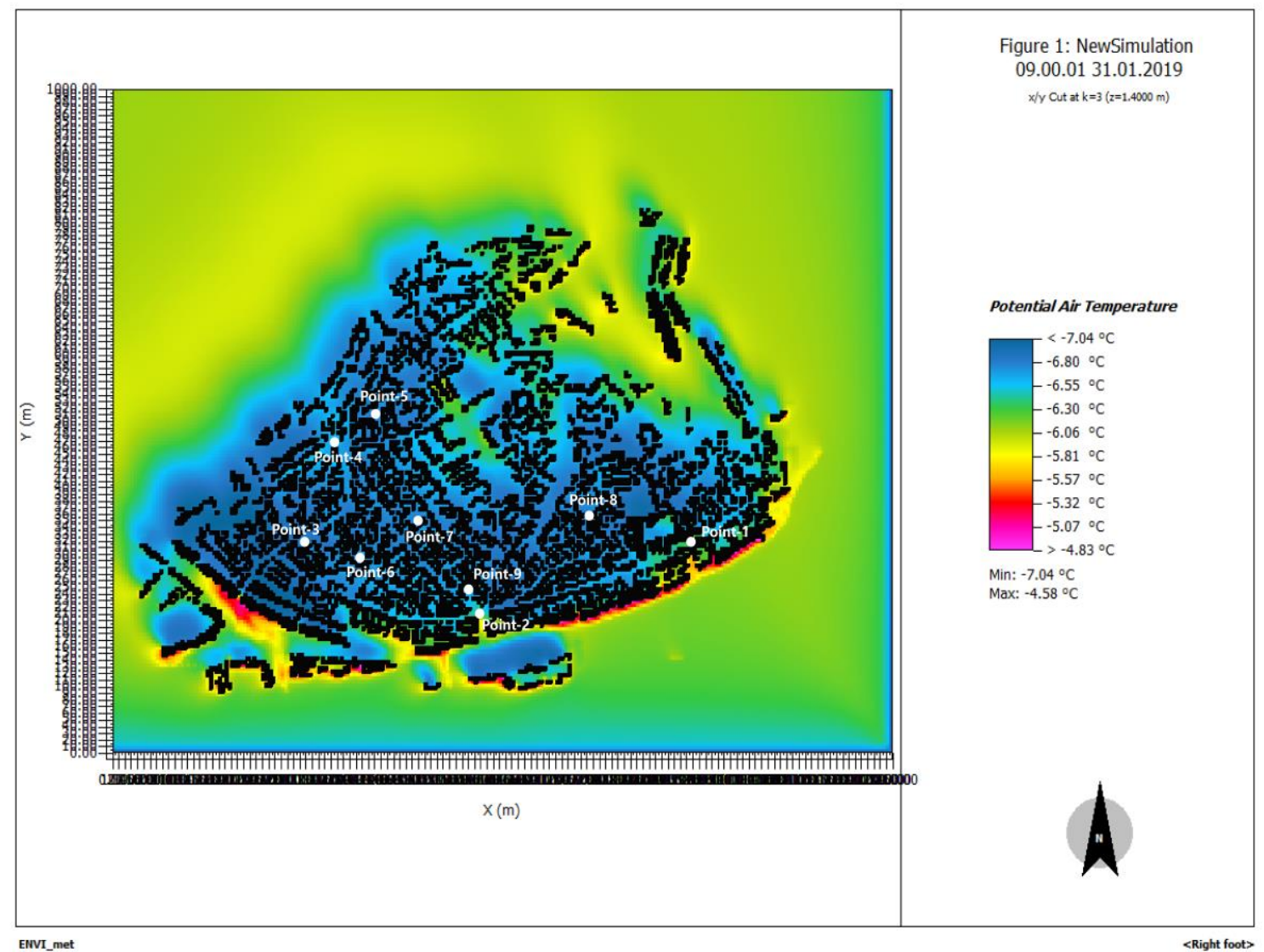

Figure. 9 The simulated results of the selected points at 9:00am on January,31th, 2019

The outputs of ENVI-met is validated against the measured results, aiming at evaluating the accuracy of the ENVI-met platform, and the hourly evolution of simulated results in each selected point with the measured data are utilized. Also, we choose two typical days for further explanation, the first case is on 31th Jan, the snowing day, and the comparison is shown in Figure 10. It's obvious that all the simulated results are lower than the measured data, and the gap of the two kinds of data in courtyard space is much higher than in outdoor space. Also, this figure shows the maximum divergence between measured (solid line) and simulated data (dash line) in point-5, up to $5.1^{\circ} \mathrm{C}$, that's due to avoid interrupting people's living in the courtyard, the logger is fixed alongside instead of the middle area.

The second typical day is on 1st Feb, the coldest day without snow, and the final comparison is shown in Figure 11, like Figure 10, each selected point refers to a different color so that it can be obviously understood the gap between the measured and simulated data. Like the first case, measured and simulated temperature in all courtyard are higher than in outdoor space, that is influenced by the reflected radiation by the surrounding building facades. 4.3 The validation between measured and simulated data

In this study, based on the previous studies [31-33], the indices including coefficient of determination (R2), systematic Root Mean Square Error (RMSEs), unsystematic Root Mean Square Error (RMSEu) and Root Mean Square Error (RMSE) are conducted for assessing the difference between the measured and simulated values. In order to get an accurate result, all mentioned 


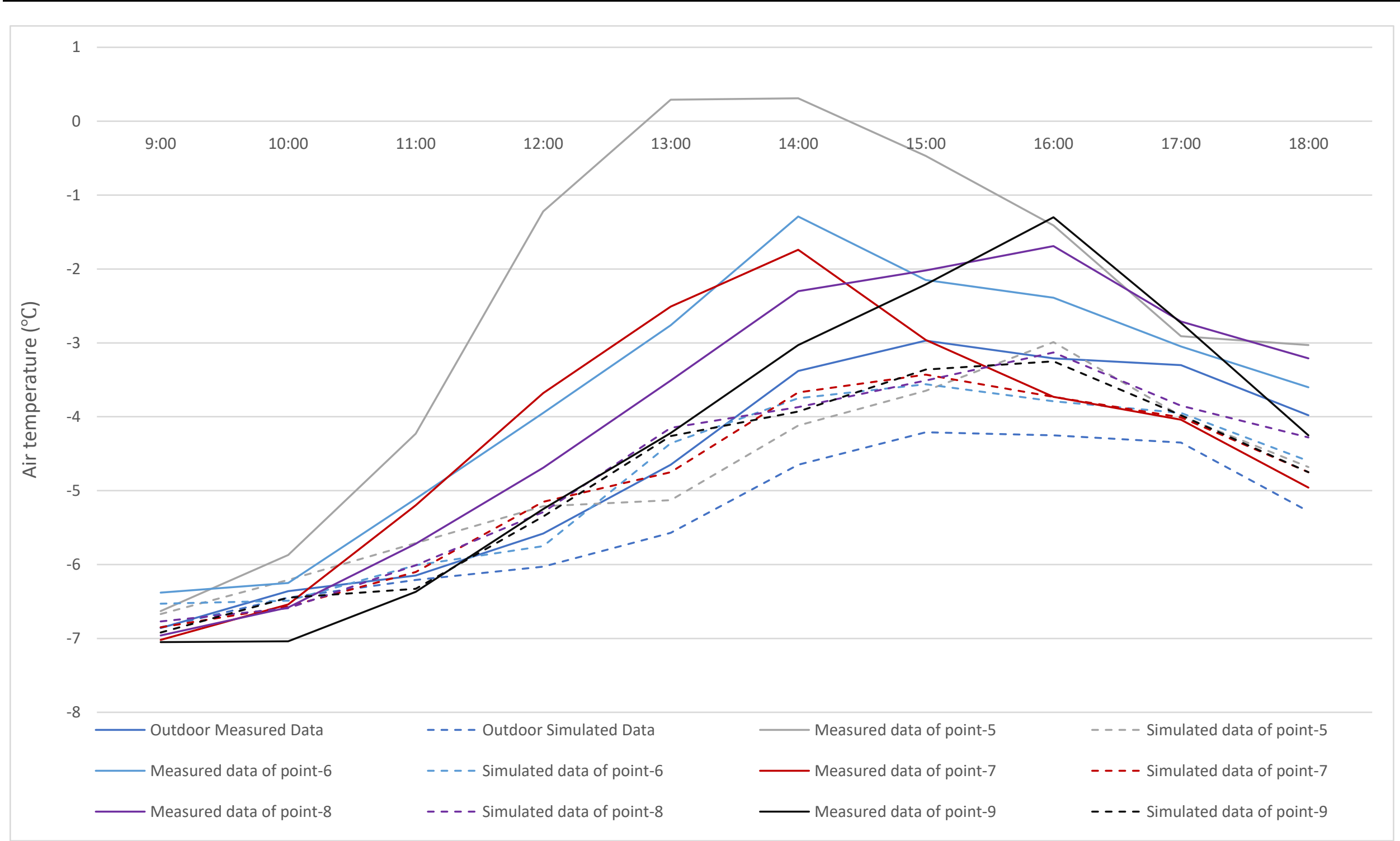




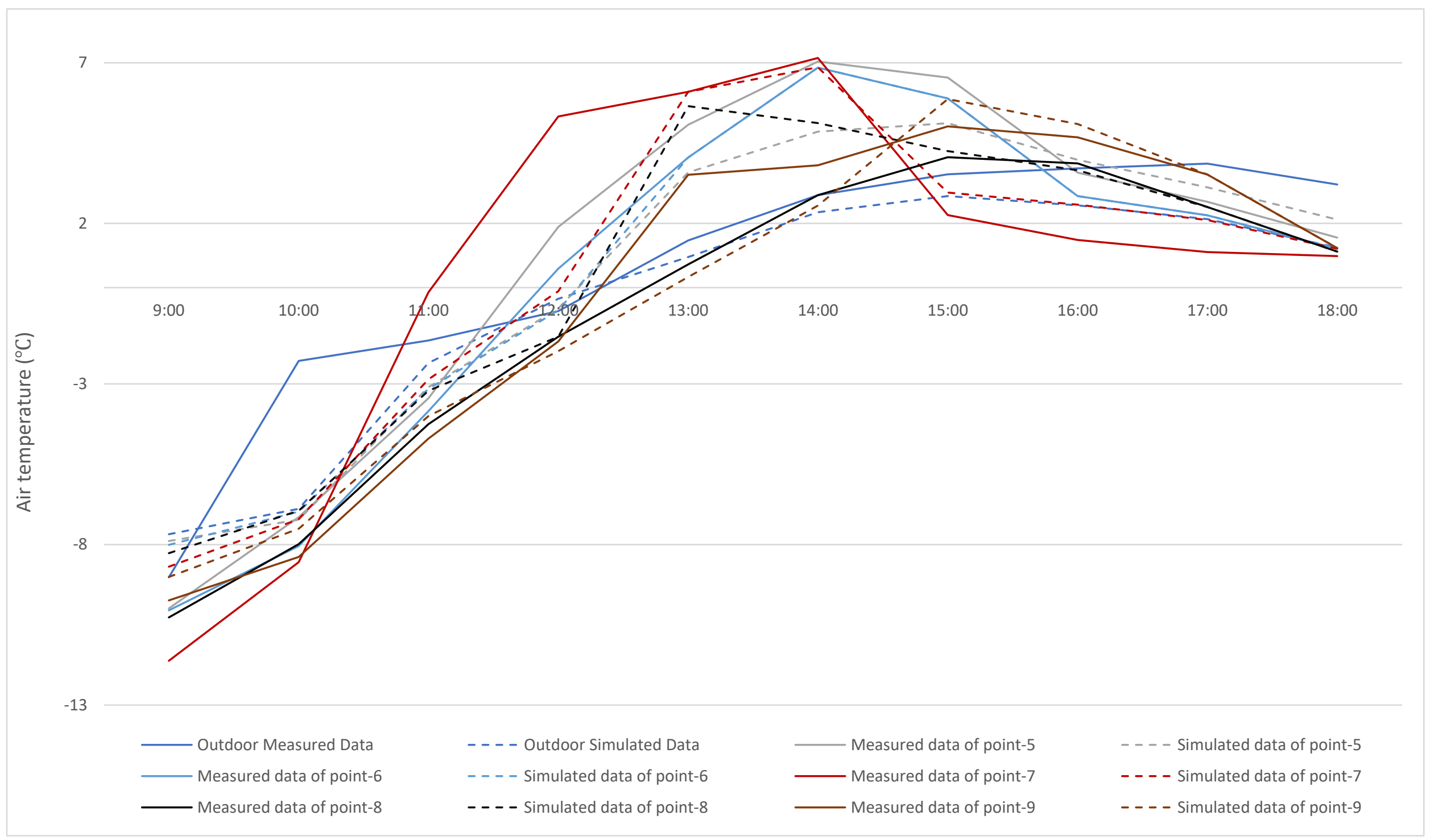


different indices must follow these values: $\mathrm{R}^{2} \rightarrow 1$, RMSEs $\rightarrow 0$, RMSE $\rightarrow 0$, RMSEu $\rightarrow$ RMSE. All mentioned indices are applied to test the air temperature.

Figure 12 shows the $\mathrm{R}^{2}$ of the courtyard space, in which we can obviously find that the latest edition of ENVI-met (v4.4.4) can forecast air temperature in cold winter accurately, with R2 changing from 0.7558 to 0.9835 .

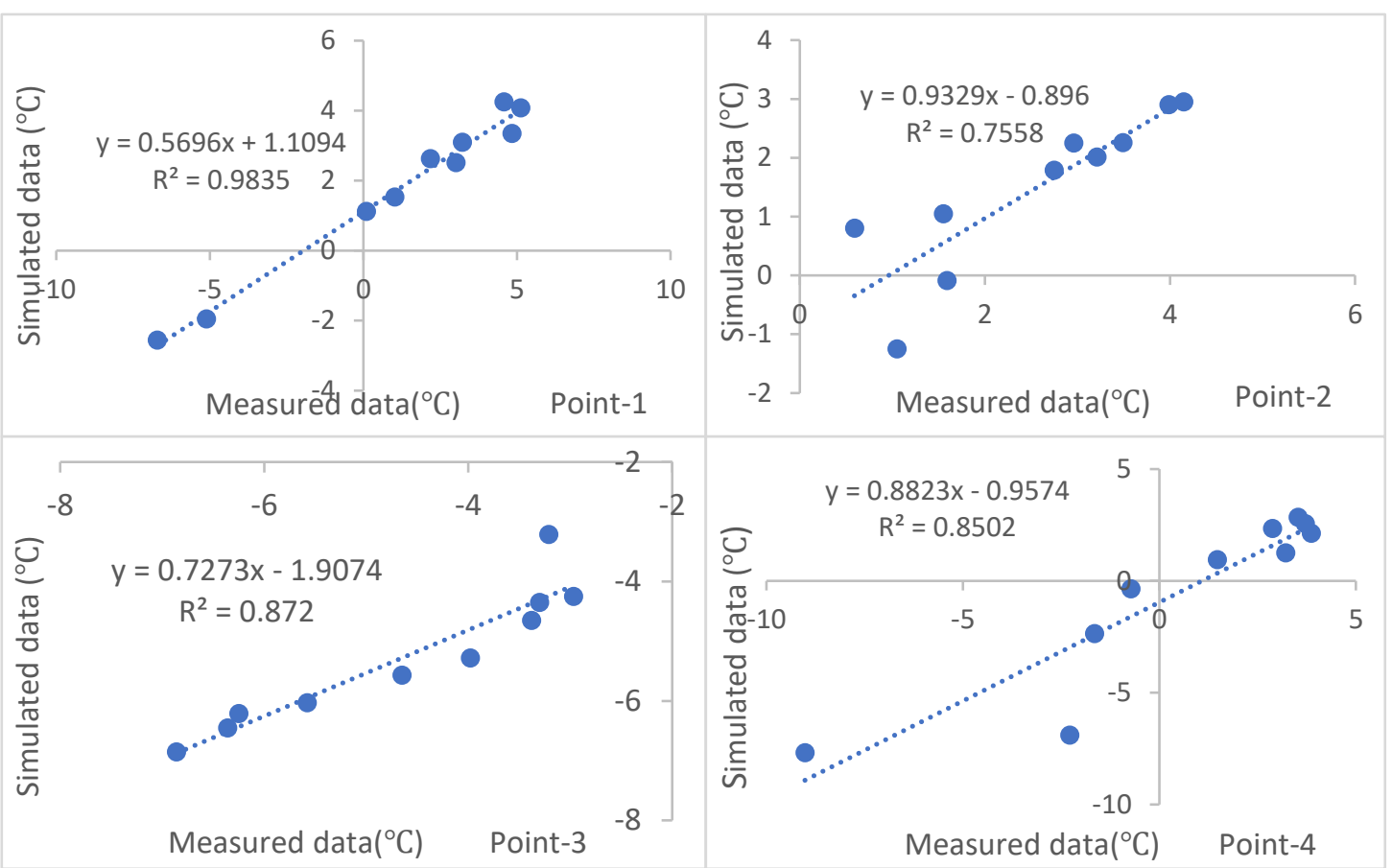

Figure 12 The comparison between measured and simulated air temperature in outdoor space

In addition, Figure 13 display the RMSE between the measured and simulated air temperature, in which point- 4 has the largest error at daytime, reaching $1.81^{\circ} \mathrm{C}$, and the point- 3 has the highest accuracy.

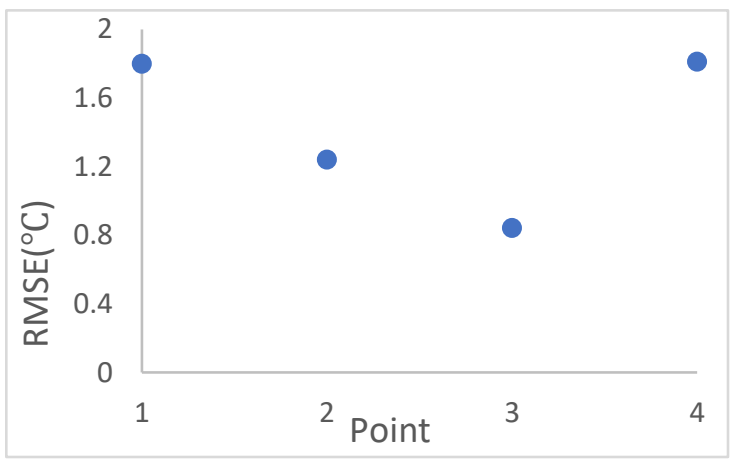

Figure 13 The RMSE between measured and simulated data in courtyard

Meanwhile, the values of RMSEs and RMSEu are conducted for assessing the accuracy of the simulation, the detailed information is shown in Table 8. The final result displays the index RMSEu is very similar to RMSE and RMSEs is close to zero, which explains that the latest edition of ENVImet v4.4.4 is a reliable tool for forecasting air temperature of winter time in outdoor space.

Table. 8 The final evaluation of the performance of ENVI-met v4.4.4 in outdoor space

\begin{tabular}{llll}
\hline & $\operatorname{RMSE}\left({ }^{\circ} \mathrm{C}\right)$ & $\operatorname{RMSEu}\left({ }^{\circ} \mathrm{C}\right)$ & $\mathrm{RMSEs}\left({ }^{\circ} \mathrm{C}\right)$ \\
\hline Point-1 & 1.79 & 1.93 & 1.46 \\
Point-2 & 1.24 & 1.45 & 1.31 \\
Point-3 & 0.84 & 0.91 & 0.79 \\
Point-4 & 1.81 & 1.86 & 1.56 \\
\hline
\end{tabular}

Like the cases in outdoor space, aforementioned parameters are all conducted in courtyard space. Figure 14 shows the final results, it is obvious that a highly accurate simulated results of the 
air temperature in courtyard is obtained, with the R2 changing from 0.8485 to 0.9365 , and a maximum RMSE is $2.01^{\circ} \mathrm{C}$ in point-5. The final values of EMSEs and RMSEu are shown in Table 9.

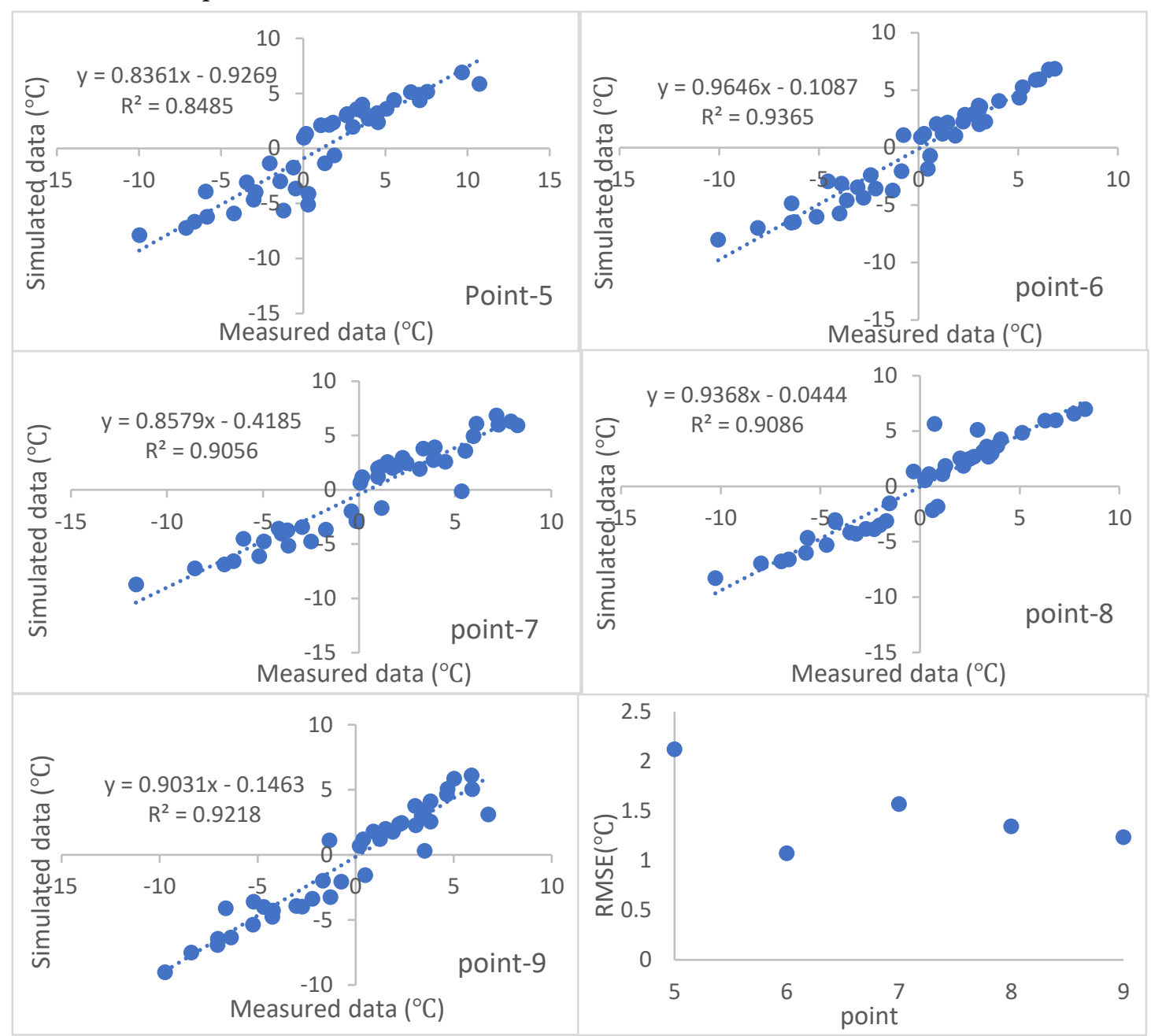

Figure 14 The correlation and RMSE between measured and simulated data in courtyard

Table 9 The final evaluation of the performance of ENVI-met v4.4.4 in courtyard

\begin{tabular}{llll}
\hline & $\operatorname{RMSE}\left({ }^{\circ} \mathrm{C}\right)$ & $\operatorname{RMSEu}\left({ }^{\circ} \mathrm{C}\right)$ & $\operatorname{RMSEs}\left({ }^{\circ} \mathrm{C}\right)$ \\
\hline Point-5 & 2.12 & 1.99 & 1.69 \\
Point-6 & 1.07 & 1.35 & 0.99 \\
Point-7 & 1.56 & 1.65 & 1.34 \\
Point-8 & 1.34 & 1.45 & 1.12 \\
Point-9 & 1.23 & 1.36 & 1.05 \\
\hline
\end{tabular}

\section{Discussions}

In the ENVI-met platform, the potential air temperature will be largely affected by the longwave radiation and the heat exchange between plants and air. But in the real world, even the data logger with thermometer screen, the air temperature will also be affected the shortwave and diffuse radiation. In such situation, ENVI-met will underestimate the real weather conditions. In this study, the final results have been tested through the analysis of different indices in accordance with previous published studies. In this case, even the obtained R2 of 0.7558 in point- 2 displaying the largest gap between measured and simulated data, it is still considered as a reliable condition by other studies. Regarding the value of RMSE $=2.12^{\circ} \mathrm{C}$ of point -5 , slightly higher than other points, it's also considered as valid in previous study [38]. The final results still can be accepted in accordance with previous studies [35-38]. 
From the analysis in previous studies about validating the utilization of ENVI-met in the simulated process of microclimate, it has been found that most of these are focused on discussing the outdoor environment, and studies about the courtyard is limited. In addition, because of the limitation of the old editions of ENVI-met, all previous studies are only focused on simulating air temperature above $0^{\circ} \mathrm{C}$. Based on this, we aim at assessing the possibility of using the latest ENVImet v4.4.4 for the prediction of the performance in simulating the air temperature in cold winter. It's concluded that even the simulated results by ENVI-met v4.4.4 is not as high as the real case, this tool is still a reliable platform for forecasting outdoor microclimate and assessing people's thermal sensation. Based on these, the researches about energy cost in outdoor environment in winter can be achieved in different new ways. We wish this study will bring a new direction for researching outdoor microclimate especially in cold winter, testing the effect of different urban design parameters including aspect ratio, sky view factor, vegetation and paving material of the ground in affecting air temperature in winter is still necessary. Also, mean radiant temperature is another very important parameter for evaluating people's thermal sensation in winter, the work of the predication of this is lacked, further studies should finish this process.

Ethical Approval and Consent to participate: Not applicable

288 Consent for publication: Written informed consent for publication was obtained from all participants.

Availability of supporting data: The datasets used or analyzed during the current study are available from the corresponding author on reasonable request.

291 Competing interests: The authors declare no conflict of interest.

292 Funding: This research has been supported by National Natural Science Foundation of China (Grant No. 51678058 ) , the China National Key R\&D Program during the 13th Five-year Plan Period (Grant No. 2019YFD1100905) and Shanxi National Science Foundation (No. 2019JM-475)-Study on the mechanism and planning regulation of urban space structure affecting wind environment.

Authors' contributions: Conceptualization, Jingyuan Zhao.; methodology, Xuan Ma.; software, Zhi Cheng validation, Xuan Ma and Lei Zhang.; formal analysis, Lei Zhang.; investigation, Lei Zhang and Xuan Ma.; resources, Jingyuan Zhao.; data curation, Xuan Ma.; writing-original draft preparation, Xuan Ma and Lei Zhang.; writing - review and editing, Jianxin Zhang. and Mengying Wang.; visualization, Xuan Ma; supervision, Jingyuan Zhao.; project administration, Jingyuan Zhao; funding acquisition, Jingyuan Zhao

Acknowledgments: This research was also supported by Huang Jin Zhi Engineering Education Development 302 Foundation Of Shanghai.

\section{References}

304 [1] C. Kwon, Form or performance in sustainable architecture, Int. J. Sustain. Build. Technol. Urban Dev. 5 (2014) 305 21-27.

306 [2] Umberto Berardi, A cross-country comparison of the building energy consumptions and their trends, 307 Resources, Conserv. Recycl. 123 (2017) 230-241.

308 [3] S. Barbhuiya, S. Barbhuiya, Thermal comfort and energy consumption in a UK educational building, Build. 309 Environ. 68 (2013) 1-11.

310 [4] Zahra Sadat Zomorodian, Mohammad Tahsildoost, Mohammadreza Hafezi, Thermal comfort in educational 311 buildings: a review article, Renew. Sustain. Energy Rev. 59 (2016) 895-906.

312 [5] Tsinghua University Building Energy Research Center, 2016 Annual Report on China Building Energy 313 Efficiency, Energy Efficiency, China Architecture \& Building Press, Beijing, 2016.

314 [6] T.F. Stocker, Q. Dahe, G.-K. Plattner, L.V. Alexander, S.K. Allen, N.L. Bindoff, F.- M. Bréon, J.A. Church, U. 315 Cubash, S. Emori, P. Forster, P. Friedlingstein, L.D. Talley,

316 D.G. Vaughan, S.-P. Xie, Technical summary, clim. Chang. 2013 phys. Sci. Basis. Contrib. Work. Gr. I to fifth 317 assess, Rep. Intergov. Panel Clim Chang. (2013) 33-115, https://doi.org/10.1017/CBO9781107415324.005.

318 [7]The introduction of cave dwelling. Available online: https://baike.baidu.com/item/juluo/6452722 (accessed on 319 1st March). 
[8] H.A. Abdulkareem, Thermal comfort through the microclimates of the courtyard. A critical review of the middle-eastern courtyard house as a climatic response, Procedia - Soc. Behav. Sci. 216 (2016) 662-674, https://doi.org/10.1016/j.sbspro. 2015.12.054.

[9] A. Ghaffarianhoseini, U. Berardi, A. Ghaffarianhoseini, Thermal performance characteristics of unshaded courtyards in hot and humid climates, Build. Environ. 87 (2015) 154-168, https://doi.org/10.1016/j.buildenv.2015.02.001.

[10] O. Al-Hafith, S. B K, S. Bradbury, P. de Wilde, Simulation of courtyard spaces in a desert climate, Energy Procedia, 9th International Conference on Applied Energy, Cardiff, UK, 2017, https://doi.org/10.1016/j.egypro.2017.12.401.

[11] J.M. Rojas-Fernández, Thermodinamics of Mediterranean Courtyards: Quantification and Applications in Eco-efficient Architectural Design, University of Seville, 2012.

[12] Ma, X.; Fukuda, H.; Zhou, D.;Wang, M. The evaluation of outdoor thermal sensation and outdoor energy efficiency of a commercial pedestrianized zone. Energies 2019, 12, 1324.

[13] X. Yang, L. Zhao, M. Bruse, Q. Meng, Evaluation of a microclimate model for predicting the thermal behavior of different ground surfaces, Build. Environ. 60 (2013) 93-104, https://doi.org/10.1016/j.buildenv.2012.11.008.

[14] Y. Wang, J. Zacharias, Landscape modification for ambient environmental improvement in central business districts - A case from Beijing, Urban For. Urban Green. 14 (2015) 8-18, https://doi.org/10.1016/j.ufug.2014.11.005.

[15] A. Qaid, D.R. Ossen, Effect of asymmetrical street aspect ratios on microclimates in hot, humid regions, Int. J. Biometeorol. 59 (2015) 657-677, https://doi.org/10. 1007/s00484-014-0878-5.

[16] H. Lee, H. Mayer, L. Chen, Contribution of trees and grasslands to the mitigation of human heat stress in a residential district of Freiburg, Southwest Germany, Landsc. V.P. López-Cabeza et al. Building and Environment 144 (2018) 129-141 Urban Plann. 148 (2016) 37-50, https://doi.org/10.1016/j.landurbplan.2015.12.004.

[17] B. Jänicke, F. Meier, M.-T. Hoelscher, D. Scherer, Evaluating the Effects of Façade Greening on Human Bioclimate in a Complex Urban Environment, Adv. Meteorol. 2015 (2015) 1-15, https://doi.org/10.1155/2015/747259.

[18] B.C. Hedquist, A.J. Brazel, Seasonal variability of temperatures and outdoor human comfort inPhoenix, Arizona, U.S.A, Build. Environ. 72 (2014) 377-388, https://doi.org/10.1016/j.buildenv.2013.11.018.

[19] C. Ketterer, A. Matzarakis, Comparison of different methods for the assessment of the urban heat island in Stuttgart, Germany, Int. J. Biometeorol. 59 (2015) 1299-1309, https://doi.org/10.1007/s00484-014-0940-3.

[20] B. Song, K. Park, Contribution of greening and high-albedo coatings to improvements in the thermal environment in complex urban areas, Adv. Meteorol. 2015 (2015) 12-21, https://doi.org/10.1155/2015/792172.

351 [21] Meteorological Organization Country. Available online: http://www.irimo.ir (accessed on 1 March 2020).

352 [22] Government of MiZhi city. Available online: http://www.mizhi.gov.cn/ (accessed on 1 March 2020).

353 [23]Introduction-ENVI_MET,(n.d.).http://www.envi-met.com/introduction/ (accessed March 1, 2020).

354 [24] Ma, X.; Fukuda, H.; Zhou, D.; Wang, M. A Study of the Pedestrianized Zone for Tourists: Urban Design on Humans' Thermal Comfort in Fo Shan City. S. China Sustain. 2019, 11, 2774.

[25] Wu,W.; Ren, H.; Yu, M.;Wang, Z. Distinct Influences of Urban Villages on Urban Heat Islands: A Case Study in the Pearl River Delta, China. Int. J. Environ. Res. Public Health 2018, 15, 1666.

[26] Erell, E.; Pearlmutter, D.; Boneh, D.; Kutiel, P.B. Effect of high-albedo materials on pedestrian heat stress in urban street canyons. Urban Clim. 2014, 10, 367-386.

360 [27] Shafique, M.; Reeho, K. Application of green-blue roof to mitigate heat island phenomena and resilient to 361 climate change in urban areas: A case study from Seoul, Korea. J. Water Land Dev. 2017, 33, 165-170.

362 [28] M. Taleghani, M. Tenpierik, A. van den Dobbelsteen, D.J. Sailor, Heat in courtyards:a validated and calibrated parametric study of heat mitigation strategies for urban courtyards in The Netherlands, Sol. Energy 103 (2014) 108-124, https://doi.org/ 
[29] A. Ghaffarianhoseini, U. Berardi, A. Ghaffarianhoseini, Thermal performance characteristics of unshaded courtyards in hot and humid climates, Build. Environ. 87 (2015) 154-168, 368 https://doi.org/10.1016/j.buildenv.2015.02.001.

369 [30] J.A. Acero, K. Herranz-Pascual, A comparison of thermal comfort conditions in four urban spaces by means of measurements and modelling techniques, Build. Environ. 93 (2015) 245-257, 371 https://doi.org/10.1016/j.buildenv.2015.06.028.

372 [31] C.S. Gusson, D.H.S. Duarte, Effects of built density and urban morphology on urban microclimate calibration of the model ENVI-met V4 for the subtropical Sao paulo, Brazil, Procedia Eng 169 (2016) 2-10, https://doi.org/10.1016/j.proeng.2016.10.001.

[32] K. Fabbri, G. Canuti, A. Ugolini, A methodology to evaluate outdoor microclimate of the archaeological site and vegetation role: a case study of the Roman Villa in Russi (Italy), Sustain. Cities Soc. 35 (2017) 107-133, https://doi.org/10.1016/j.scs.2017.07.020.

378 [33] C.J. Willmott, Some Comments on the Evaluation of Model Performance, (n.d.). 379 https://journals.ametsoc.org/doi/pdf/10.1175/1520-0477.

380 [34] D.H.S. Duarte, P. Shinzato, C. Dos, S. Gusson, C.A. Alves, The impact of vegetation on urban microclimate to counterbalance built density in a subtropical changing climate, Urban Clim 14 (2015) 224-239, https://doi.org/10.1016/j.uclim.2015.09. 006.

383 [35] C. Ketterer, A. Matzarakis, Comparison of different methods for the assessment of the urban heat island in 384 Stuttgart, Germany, Int. J. Biometeorol. 59 (2015) 1299-1309, https://doi.org/10.1007/s00484-014-0940-3.

[36] M. Taleghani, L. Kleerekoper, M. Tenpierik, A. Van Den Dobbelsteen, Outdoor thermal comfort within five different urban forms in the Netherlands, Build. Environ. 83 (2015), https://doi.org/10.1016/j.buildenv.2014.03.014.

388 [37] Zhang, G.; He, B.-J.; Zhu, Z.; Dewancker, B.J. Impact of morphological characteristics of green roofs on 389 pedestrian cooling in subtropical climates. Int. J. Environ. Res. Public Health 2019, 16, 179.

390 [38] B. Song, K. Park, Contribution of greening and high-albedo coatings to improvements in the thermal 391 environment in complex urban areas, Adv. Meteorol. 2015(2015) 12-21, https://doi.org/10.1155/2015/792172. 


\section{Figures}

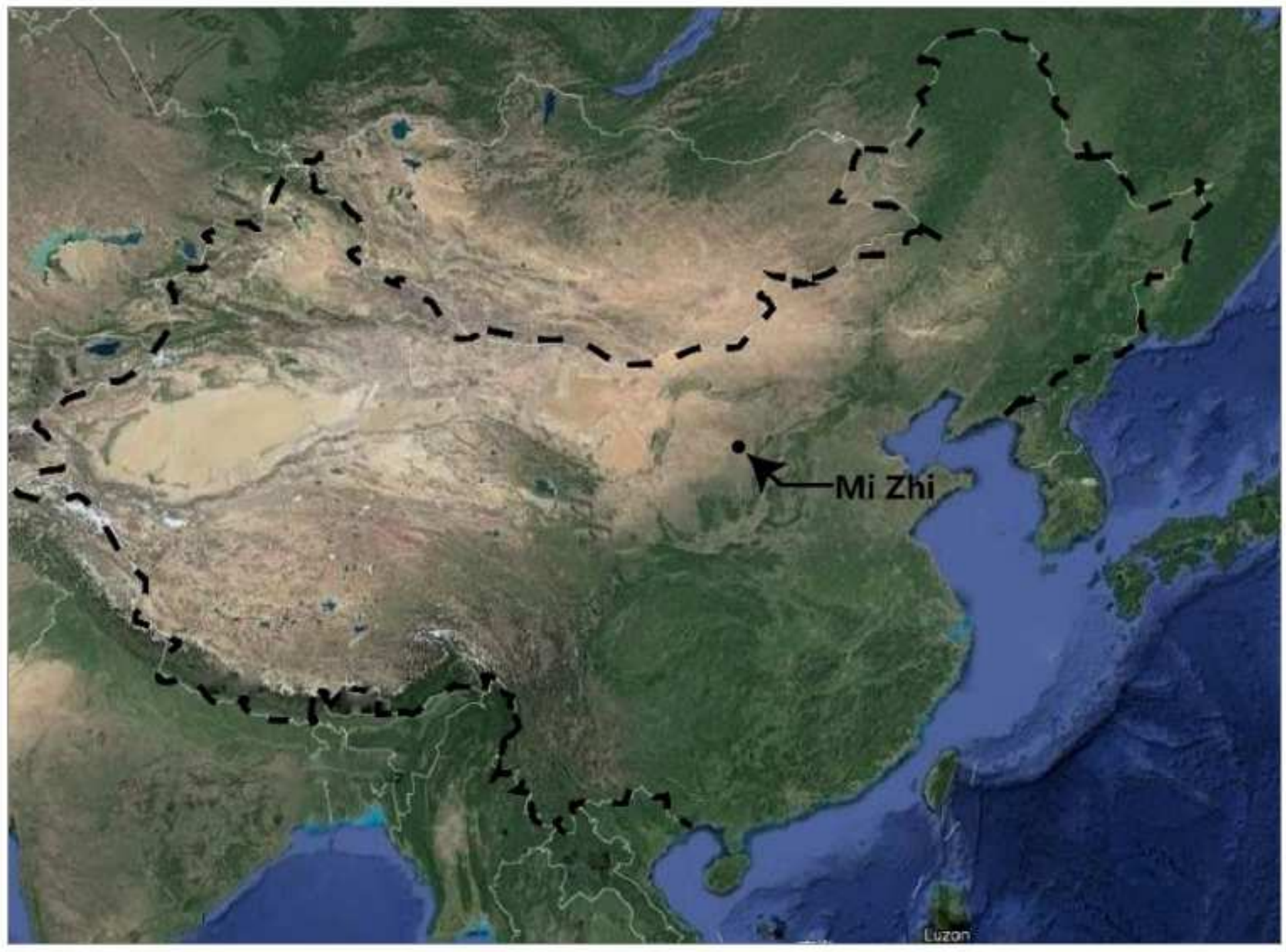

\section{Figure 1}

The location of the Mi Zhi city. Note: The designations employed and the presentation of the material on this map do not imply the expression of any opinion whatsoever on the part of Research Square concerning the legal status of any country, territory, city or area or of its authorities, or concerning the delimitation of its frontiers or boundaries. This map has been provided by the authors. 


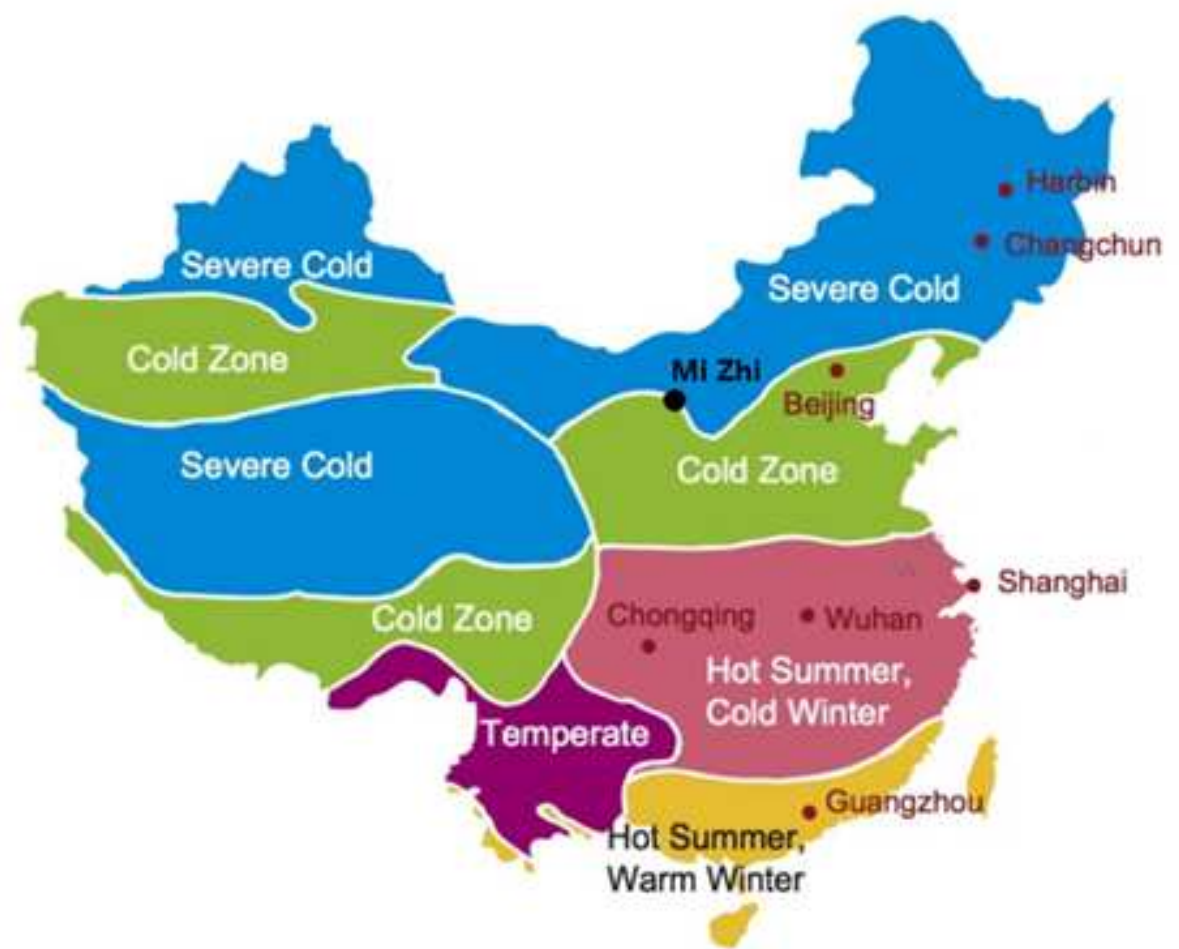

Figure 2

The climate zone of the Mi Zhi city Note: The designations employed and the presentation of the material on this map do not imply the expression of any opinion whatsoever on the part of Research Square concerning the legal status of any country, territory, city or area or of its authorities, or concerning the delimitation of its frontiers or boundaries. This map has been provided by the authors.

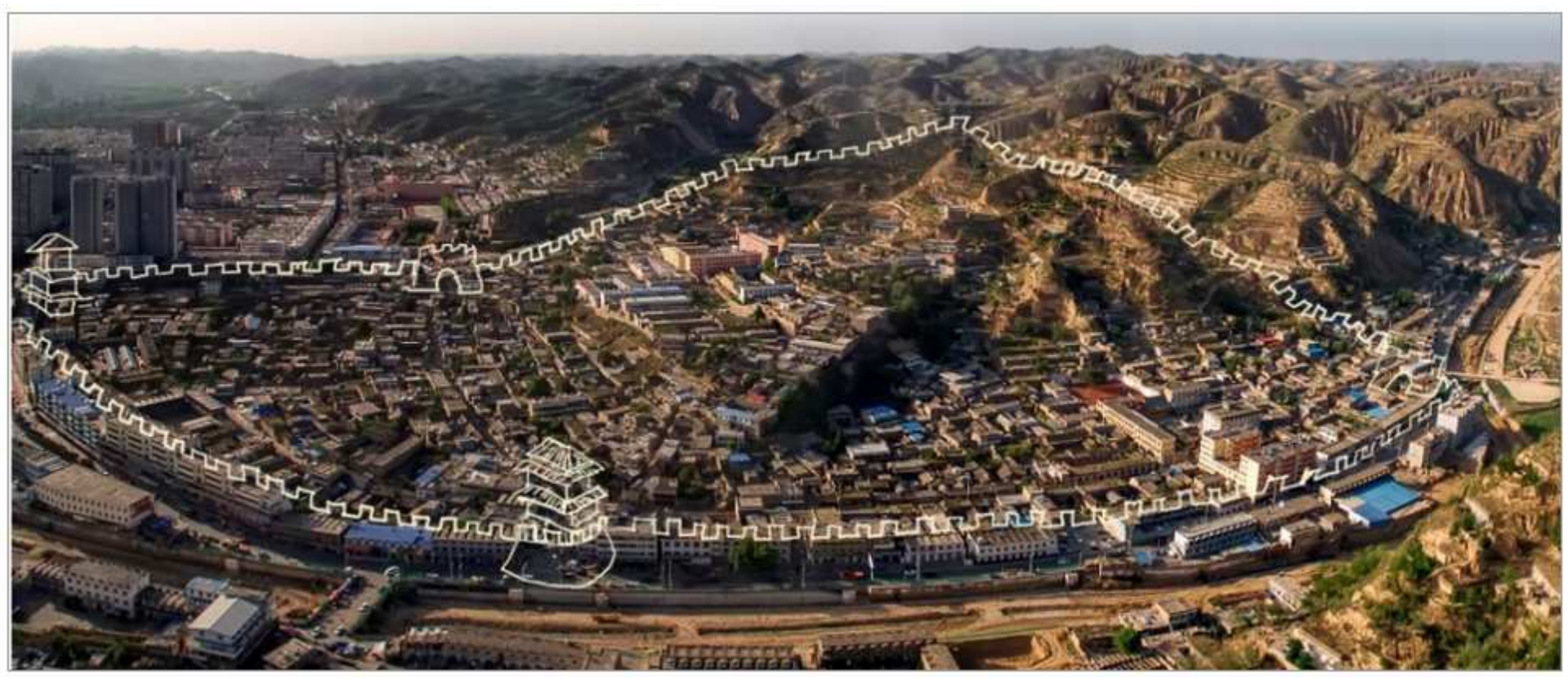

Figure 3

The ancient cave dwelling settlement in Mi Zhi city 


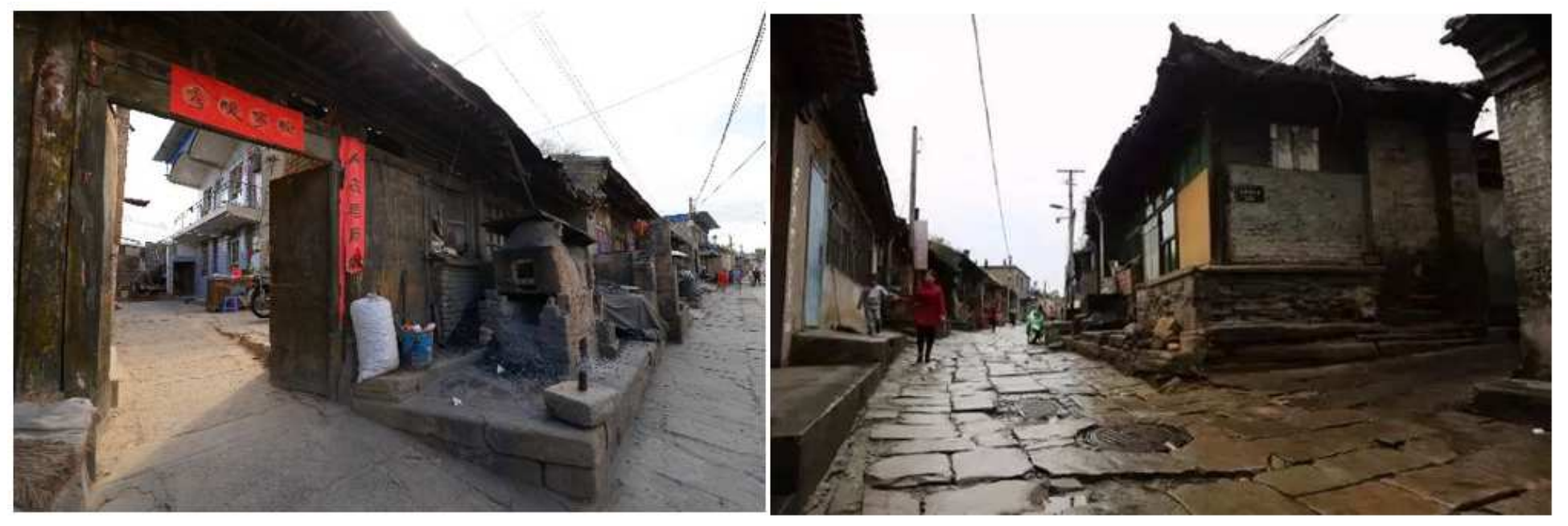

Figure 4

The existing dwellings in Mi Zhi city

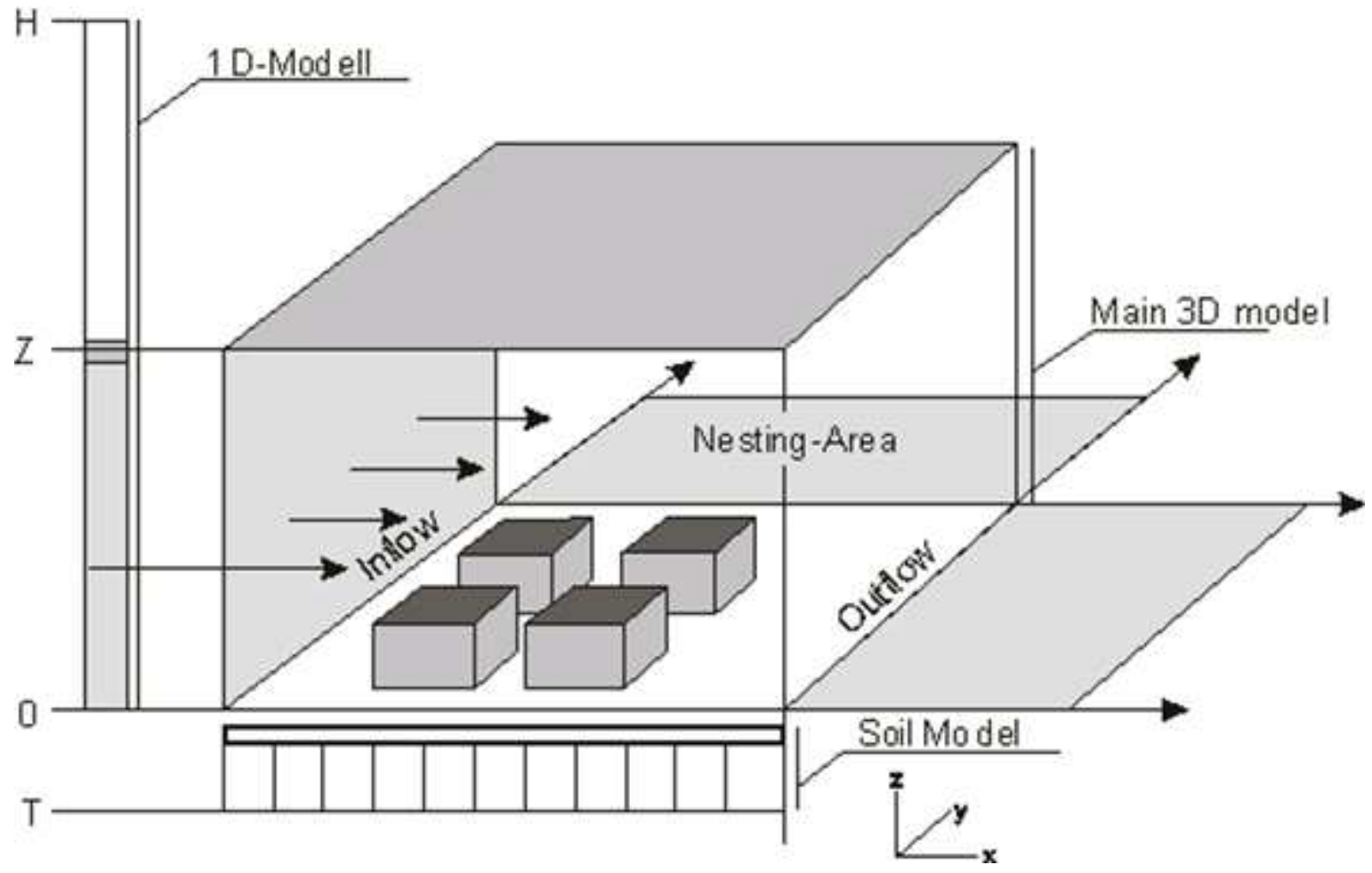

Figure 5

The schematic overview of the ENVI-met model 


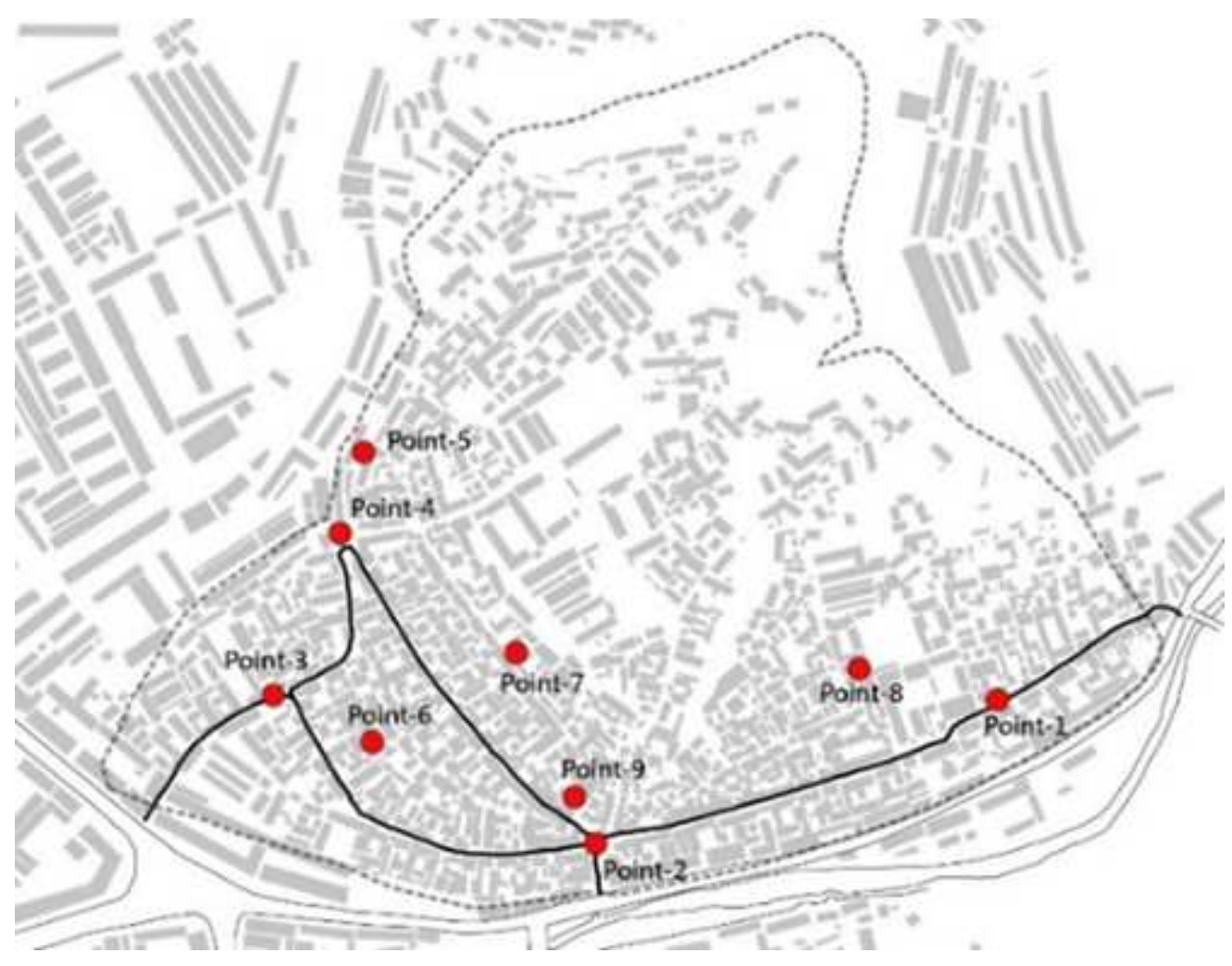

Figure 6

The selected points in the on-site measurement 

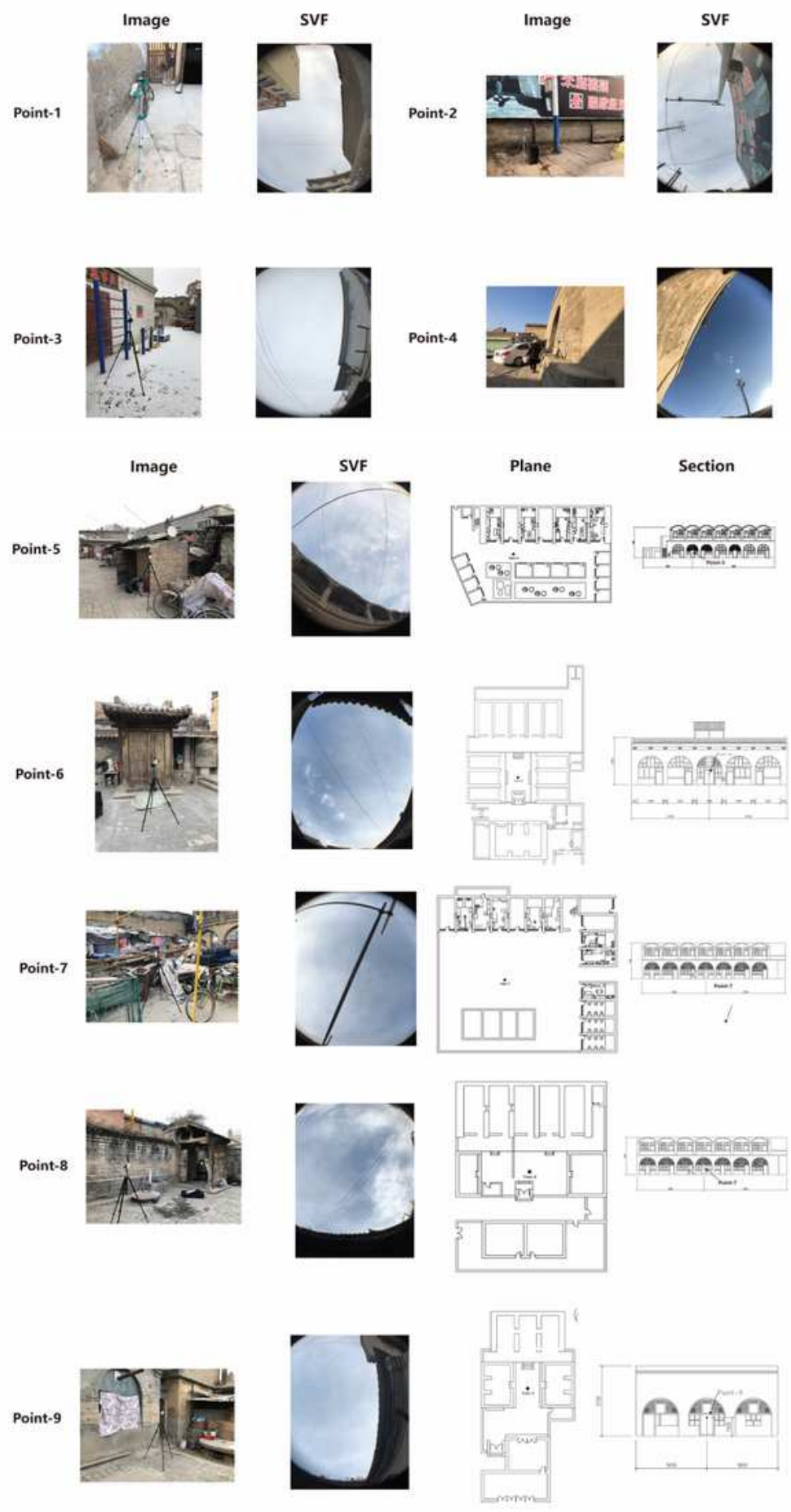

Figure 7

The detailed information of the selected points 


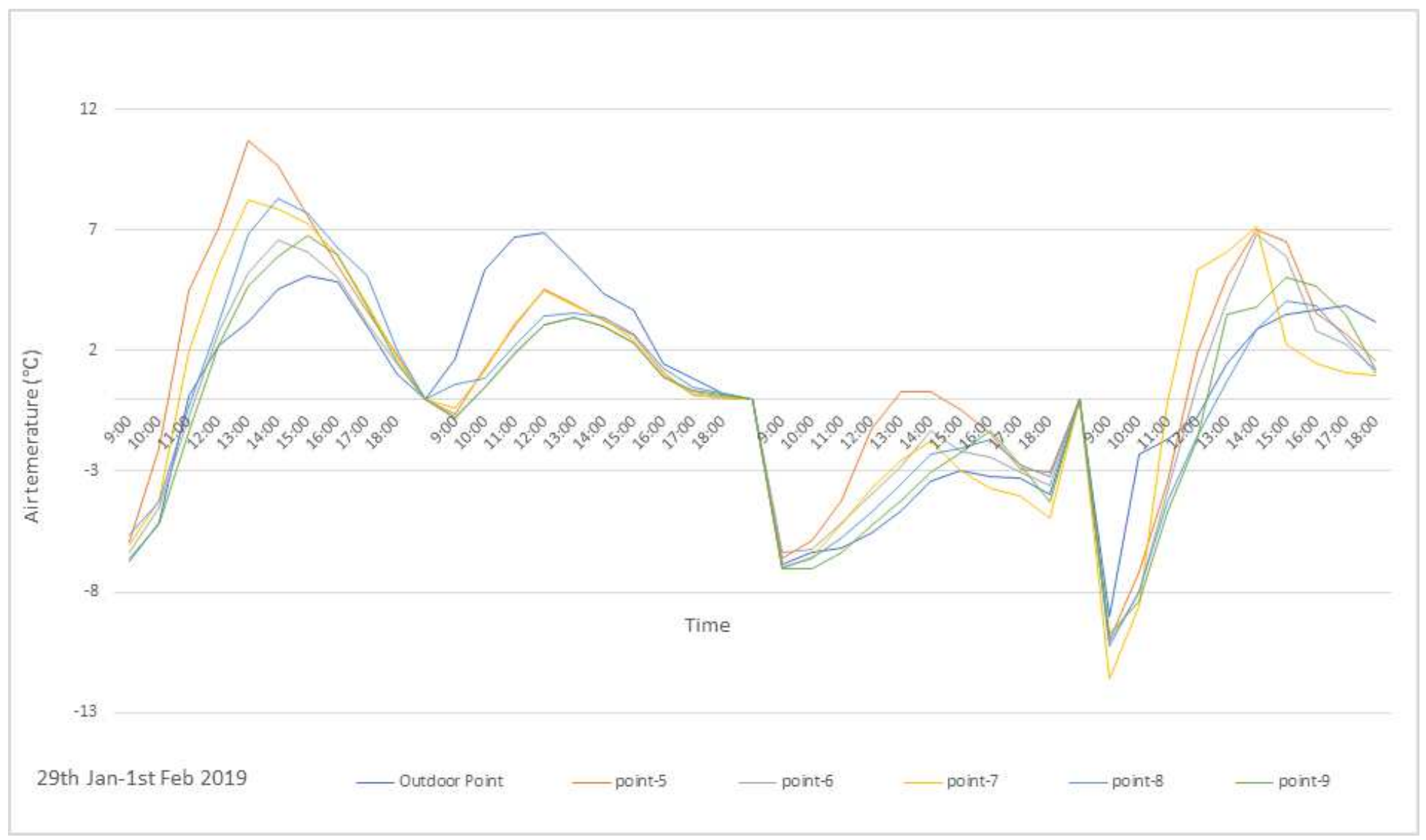

\section{Figure 8}

Measured data of air temperature in outdoor and courtyard space 


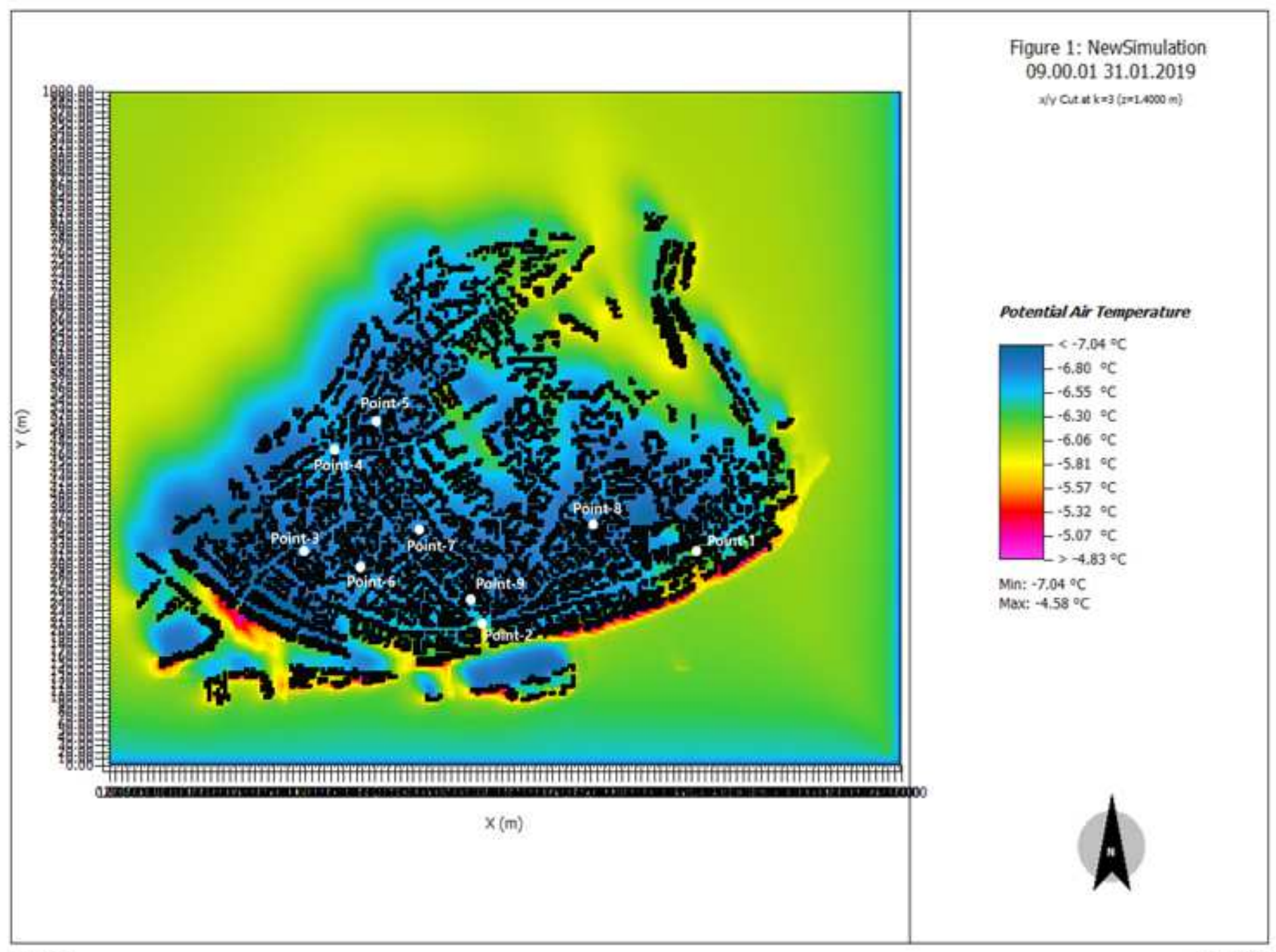

Euvi_met

eright foets

\section{Figure 9}

The simulated results of the selected points at 9:00am on January,31th, 2019 


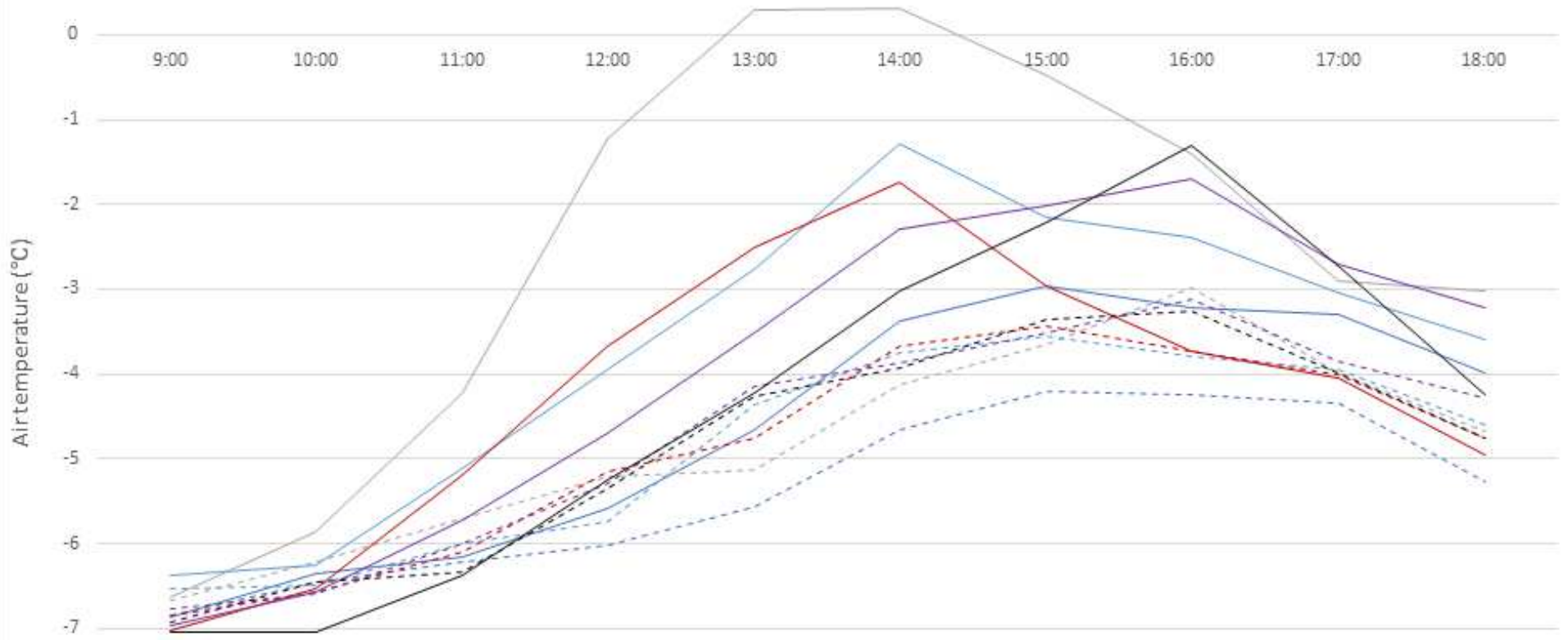

$-8$

\begin{tabular}{|c|c|c|c|}
\hline Outdoor Measured Data & ..... Outdoor Simulated Data & Measured data of point -5 & ..... Simulated data of point -5 \\
\hline - Measured data of point- 6 & -...- Simulated data of point -6 & Measured data of point -7 & [.... Simulated data of point -7 \\
\hline Measured data of & .... Simulated data of point-8 & - Measured data of point-9 & -... Simulated data of point-9 \\
\hline
\end{tabular}

\section{Figure 10}

The comparison between measured and simulated data on January31th

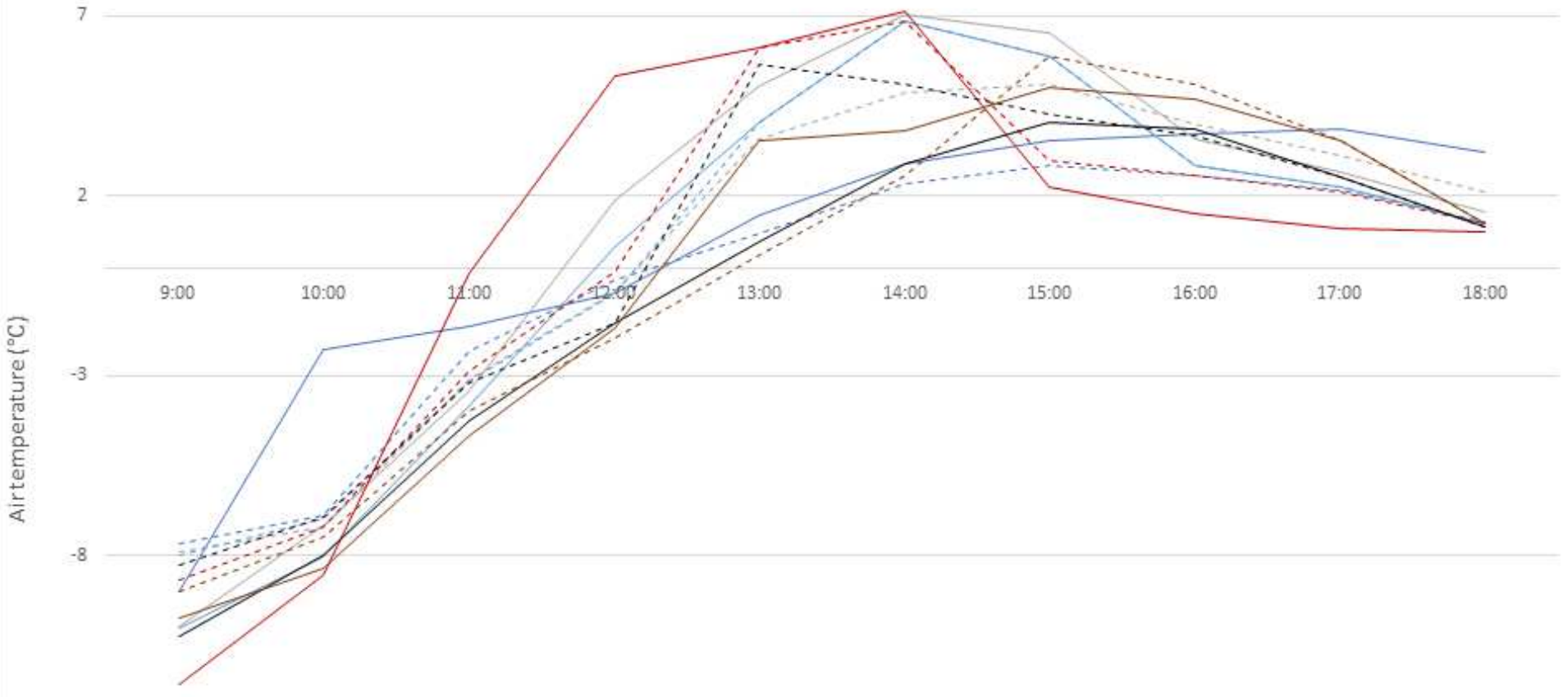

$-13$

\begin{tabular}{|c|c|}
\hline Outdoor Measured Data & ...... Outdoor Simulated Data \\
\hline oint -6 & .... si \\
\hline sured d & \\
\hline
\end{tabular}

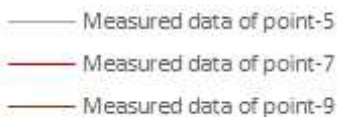

-... Simulated data of point-5

-...- Simulated data of point-7

-.... Simulated data of point-9 


\section{Figure 11}

The comparison between measured and simulated data on February 1st

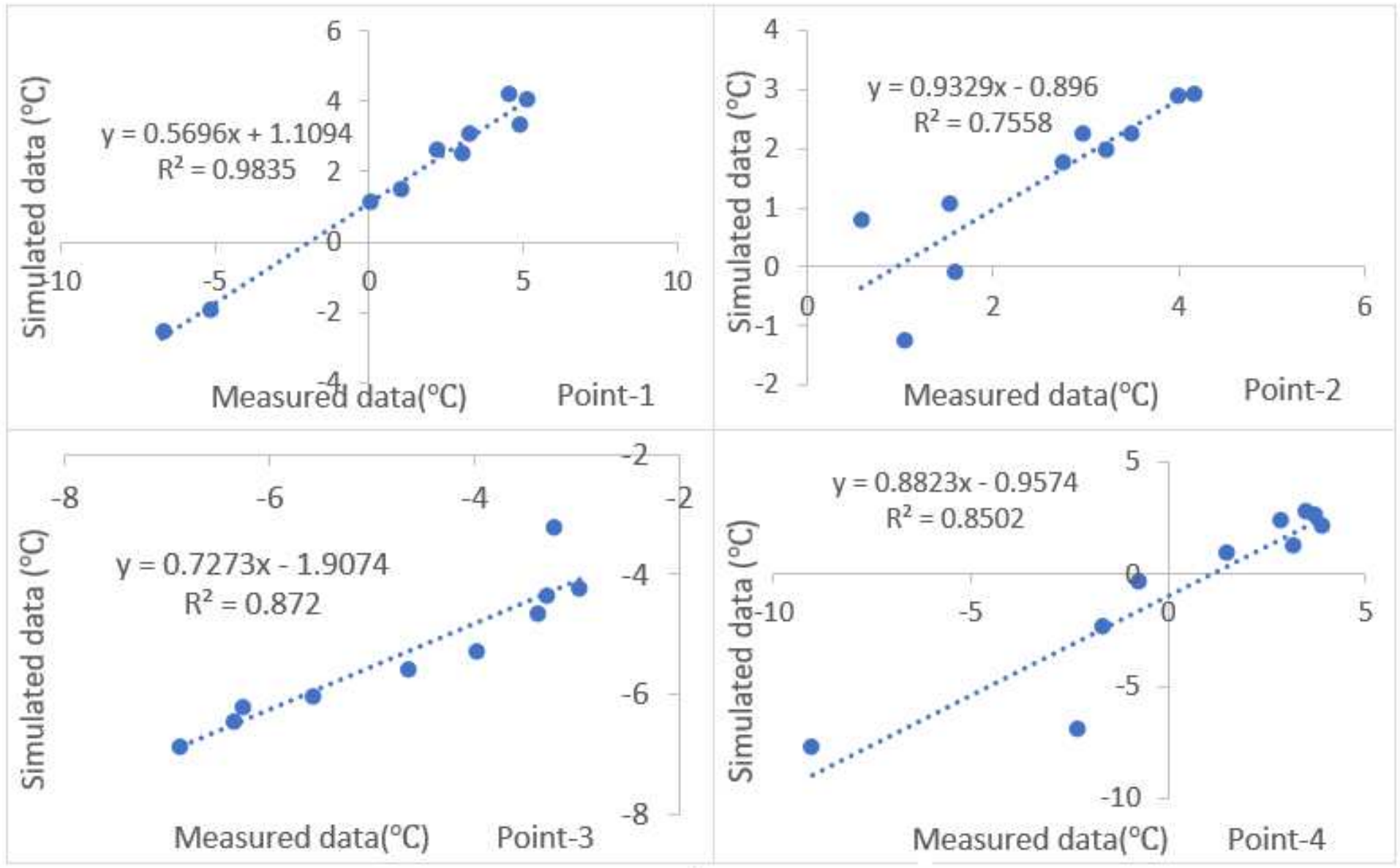

Figure 12

The comparison between measured and simulated air temperature in outdoor space

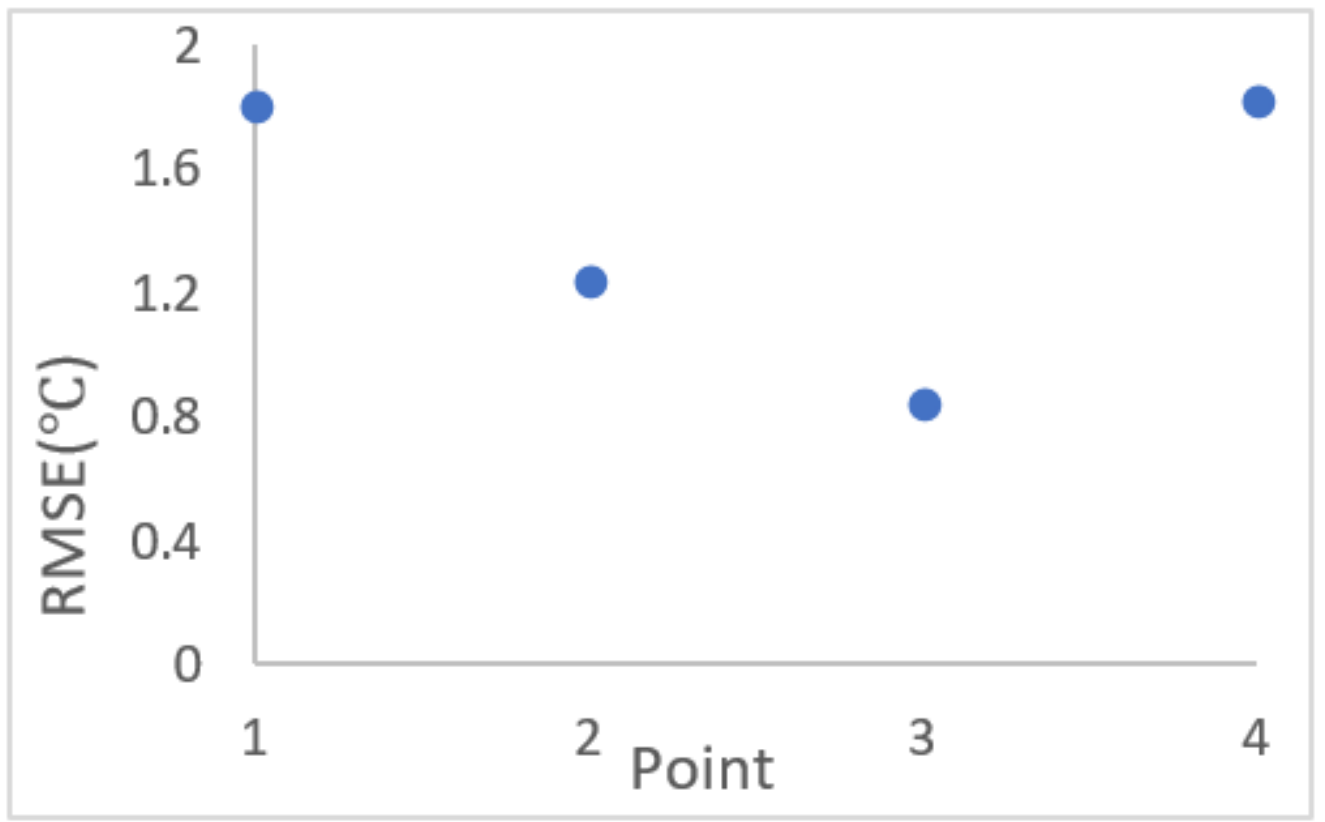


Figure 13

The RMSE between measured and simulated data in courtyard

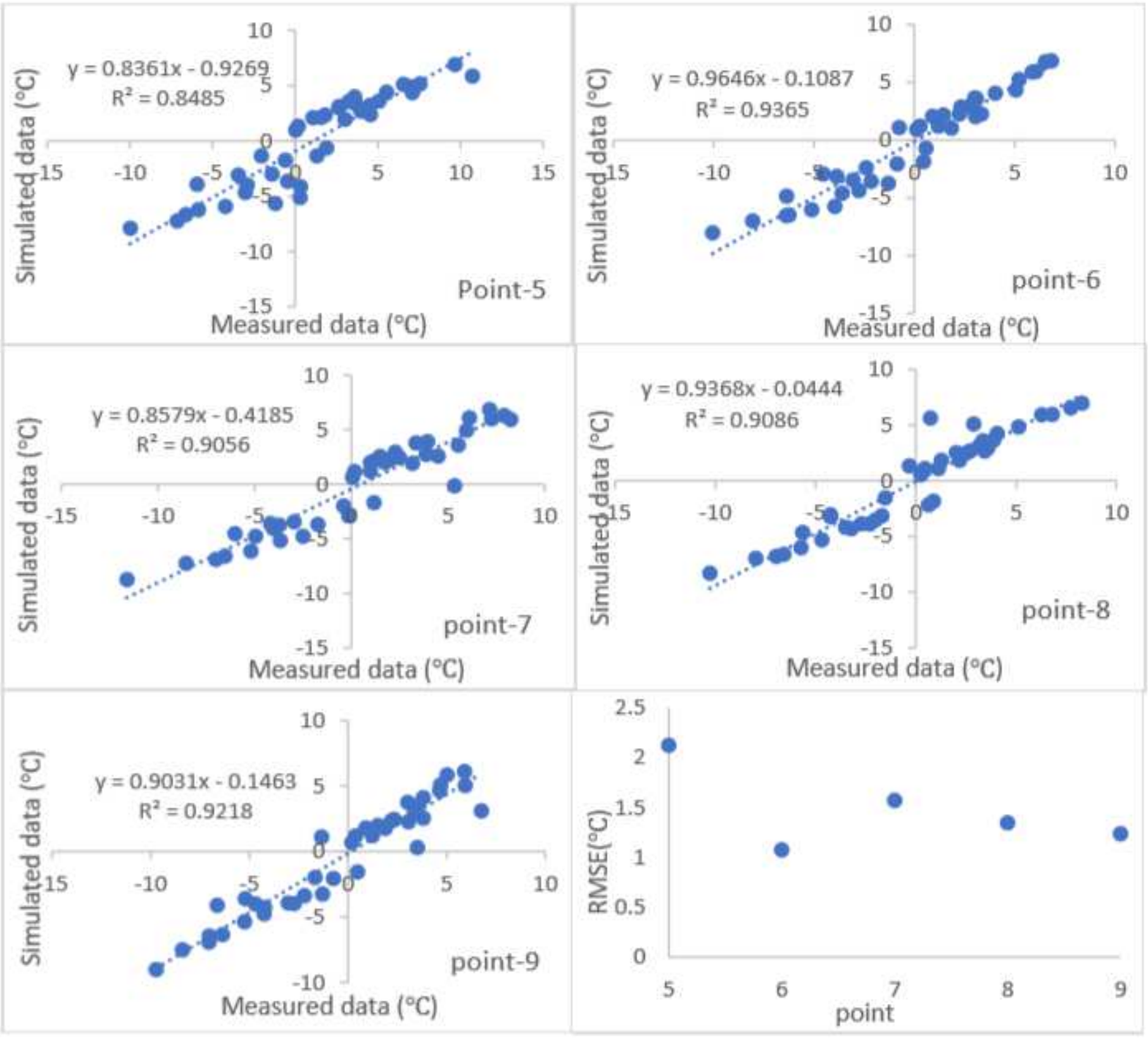

Figure 14

The correlation and RMSE between measured and simulated data in courtyard 